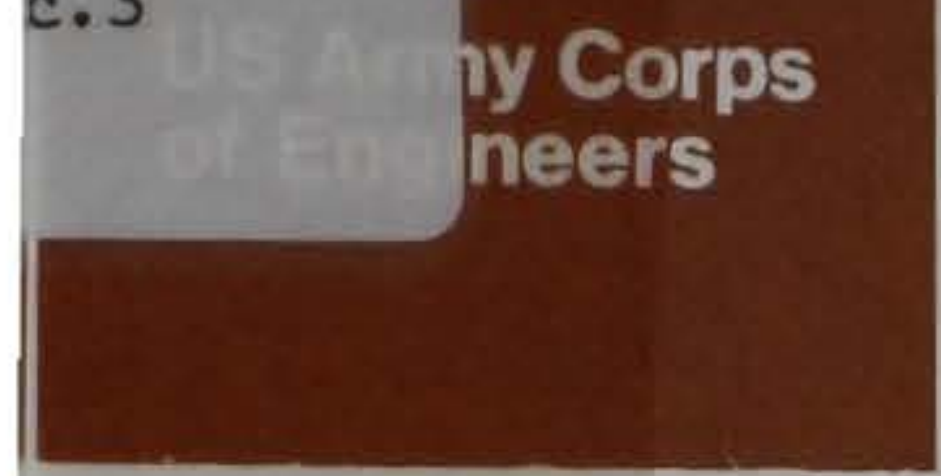

\title{
IMPROVED STRENGTH DESIGN OF REINFORCED CONCRETE HYDRAULIC STRUCTURES - RESEARCH SUPPORT
}

\author{
by
}

Stanley C. Woodson

Structures Laboratory

and

William A. Price

Information Technology Laboratory

DEPARTMENT OF THE ARMY

Waterways Experiment Station, Corps of Engineers

3909 Halls Ferry Road, Vicksburg, Mississippi 39180-6199

\section{US-CE-C property OF the UNITED STATES GOVERNMENT}
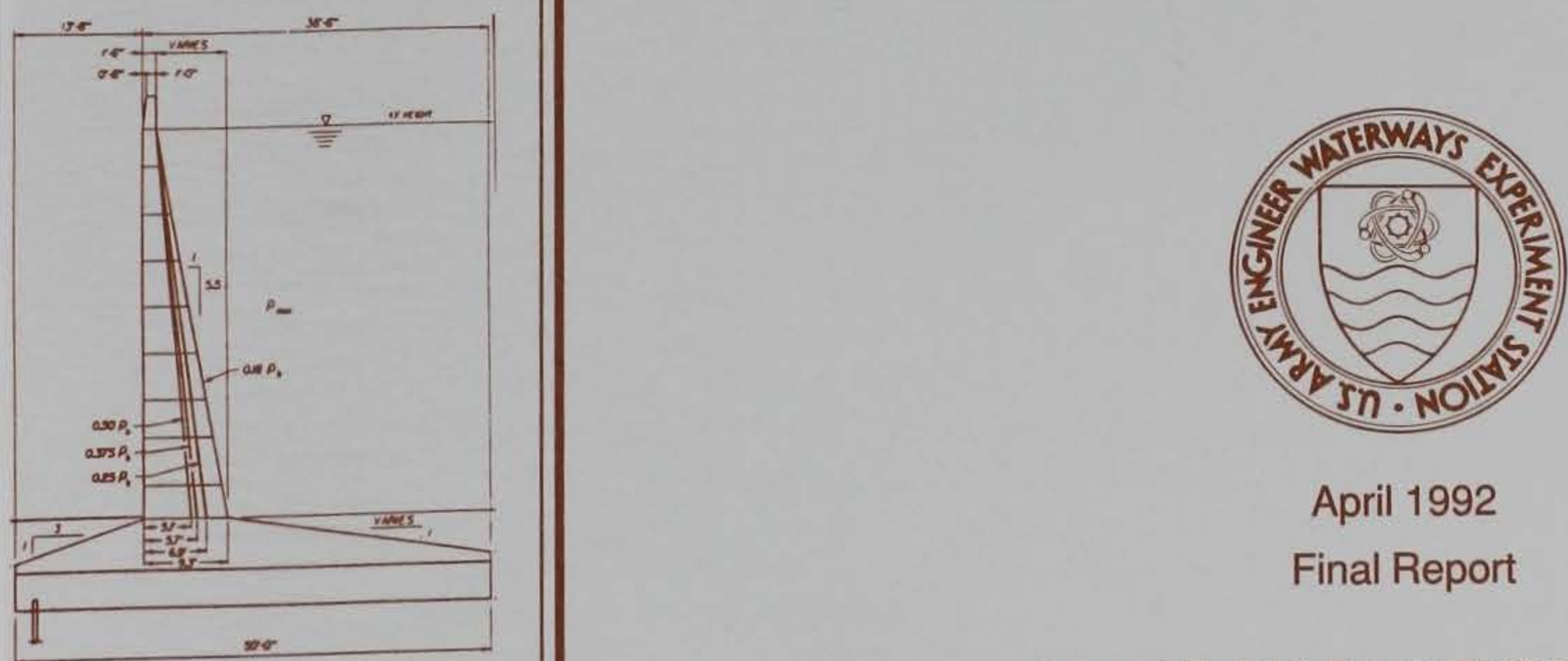

April 1992

Final Report

Approved For Public Release; Distribution Is Unlimited

RESEARCH LIBRARY

US ARMY ENGINEER WATERWAYS

EXPERIMENT STATION

VICKSBURG, MISSISSIPPI

Prepared for DEPARTMENT OF THE ARMY

US Army Corps of Engineers

Washington, DC 20314-1000 
Public reporting burden for this collection of information is estimated to average 1 hour per response, inciuding the time for reviewing instructions, searching existing data sources, gathering and maintaining the data needed, and completing and reviewing the collection of information. Send comments regarding this burden estimate or any other aspect of this collection of information, including suggestions for reducing this burden, to Washington Headquarters Services. Directorate for intormation Operations and Reports, 1215 jefferson
Davis Highway. Suite 1204, Arlington, VA 22202-4302, and to the Otfice of Management and Budget, Paperwork Reduction Project (0704-0188), Washington, DC 20503.

\begin{tabular}{|l|l|l|}
\hline 1. AGENCY USE ONLY (Leave blank) & 2. REPORT DATE & 3. REPORT TYPE AND DATES COVERED
\end{tabular} \begin{tabular}{|l|l|l} 
& April 1992 & Final report \\
\hline 4. TITLE AND SUBTITLE
\end{tabular} 5. FUNDING NUMBERS

Improved Strength Design of Reinforced Concrete

Hydraulic Structures - Research Support

6. AUTHOR(S)

Stanley C. Woodson

William A. Price

7. PERFORMING ORGANIZATION NAME(S) AND ADDRESS(ES)

8. PERFORMING ORGANIZATION REPORT NUMBER

USAE Waterways Experiment Station

Structures and Information Technology Laboratories

$3909 \mathrm{Halls}$ Ferry Road

Vicksburg, MS 39180-6199

9. SPONSORING/MONITORING AGENCY NAME(S) AND ADDRESS(ES)

Technical Report

SL-92-11

10. SPONSORING/MONITORING AGENCY REPORT NUMBER

US Army Corps of Engineers

Washington, DC 20314-1000

\section{SUPPLEMENTARY NOTES}

Available from National Technical Information Service, 5285 Port Royal Road, Springfield, VA 22161

12a. DISTRIBUTION/AVAILABILITY STATEMENT

12b. DISTRIBUTION CODE

Approved for public release; distribution is unlimited

\section{ABSTRACT (Maximum 200 words)}

Strength design (SD) criteria for reinforced concrete hydraulic structures (RCHS) have been based on a procedure that resulted in equivalence with the working stress method given in Engineer Manual 1110-1-2101, dated 1963. Recent studies have been directed toward reducing the conservatism associated with the working-stress-equivalent SD procedure, thereby, improving the economy of RCHS.

Parametric studies indicate that an adjustment to the ACI 318-89 load factors results in close agreement with working stress designs for tension-control failures and for pure compression failures. These are the failure zones that are of primary interest for the design of RCHS. Also, serviceability is a primary concern for RCHS. In regard to serviceability, a primary parameter considered in this study was the ratio $\rho_{\max }$ (steel ratio as a fraction of the balanced reinforcement ratio).

14. SUBJECT TERMS

Compression failures

Reinforced concrete hydraulic structures

17. SECURITY CLASSIFICATION 18. SECURITY CLASSIFICATION OF REPORT
UNCLASSIFIED
Strength design

Tension control failures
19. SECURITY CLASSIFICATION OF ABSTRACT UNCLASSIFIED 
This study was conducted by personnel of the US Army Engineer Waterways Experiment Station (WES) under the sponsorship of Headquarters, US Army Corps of Engineers (HQUSACE). The Technical Monitor was Dr. Tony Liu, HQUSACE.

This work was conducted under the supervision of Mr. Bryant Mather, Director, Structures Laboratory (SL); and Mr. James T. Ballard, Assistant Director, SL; Dr. Jimmy P. Balsara, Chief, Structural Mechanics Division (SMD), SL; Dr. N. Radhakrishnan, Director, Information Technology Laboratory (ITL), and Mr. Paul K. Senter, former Chief, Computer-Aided Engineering Division (CAED), ITL, and Dr. Robert L. Hall, SMD, monitored this study. Mr. Stanley C. Woodson, SMD, and Mr. William A. Price, CAED, performed the study and prepared this report.

At the time of publication of this report, Director of WES was $\mathrm{Dr}$. Robert W. Whalin. Commander and Deputy Director was COL Leonard G. Hasse11, EN. 
CONVERSION FACTORS, NON-SI TO SI (METRIC)

UNITS OF MEASUREMENT

PART I: INTRODUCTION

\section{Background}

Objective

Scope

PART II: DISCUSSION OF RESEARCH

Reinforcing Bars - Availability

Crack Control

Section Strength

Comparison with Working Stress Method

Effects of $\rho_{\max }$ on Cost and Constructibility

Effects of $\rho_{\max }$ on Design of a $\mathrm{T}$-Wall

PART III: CONCLUSIONS AND RECOMMENDATIONS

Conclusion 25

Recommendations

REFERENCES

Figures 1-29 


\section{CONVERSION FACTORS, NON-SI TO SI (METRIC) \\ UNITS OF MEASUREMENT}

Non-SI units of measurement used in this report can be converted to SI (metric) units as follows:

\section{Multiply}

cubic yards

feet

inches

kips (force)

kip-feet

kips (force) per inch

kips (force) per square foot

kips (force) per square inch

pounds (force)

pounds (force) per square inch

\begin{tabular}{|c|c|}
\hline By & To Obtain \\
\hline 0.7645549 & cubic metres \\
\hline 0.3048 & metres \\
\hline 2.54 & centimetres \\
\hline 4.448222 & kilonewtons \\
\hline 0.1751269 & kilonewtons per metre \\
\hline 175.1268 & kilonewtons per metre \\
\hline 47.88026 & kilopascals \\
\hline 6.894757 & megapascals \\
\hline 4.448222 & newtons \\
\hline 6.894757 & kilopascals \\
\hline
\end{tabular}




\section{IMPROVED STRENGTH DESIGN OF REINFORCED CONCRETE \\ HYDRAULIC STRUCTURES - RESEARCH SUPPORT}

\section{PART I: INTRODUCTION}

\section{Background}

1. In general, existing reinforced concrete hydraulic structures (RCHS) designed by the Corps, using the working stress method of EM 1110-1-2101 (Headquarters, Department of the Army 1963) have held up extremely well. The Corps began using strength design (SD) methods in 1981 to stay in step with industry, universities, and other engineering organizations. Engineer Technical Letter (ETL) 1110-2-265 (Headquarters, Department of the Army 1981) was the first document providing guidance issued by the Corps concerning the use of SD methods for hydraulic structures. The labor-intensive requirements of this ETL regarding the application of multiple load factors, as well as the fact that some load-factor combination conditions resulted in a less conservative design than if working stress methods were used, resulted in the development of ETL 1110-2-312 (Headquarters, Department of the Army 1988).

2. The revised load factors in ETL 1110-2-312 were intended to assure that the resulting design was as conservative as if working stress methods were used. Also, the single load factor concept was introduced. The guidance in this ETL differs from the American Concrete Institute (ACI) Committee 318 (ACI 1989), primarily in the load factors, the concrete stress-strain relationship, and the yield strength of Grade 60 reinforcement. ETL 1110-2-312 guidance was intended to result in designs equivalent to those resulting when working stress methods are used.

3. The research discussed in this report was performed in support of the development of a new Engineer Manual for SD of RCHS. The manual is currently in draft form and has been distributed to the Corps field offices for review. The new Engineer Manual modifies and expands the guidance in ETL 1110-2-312 with an approach similar to that of ACI 350R-89 (ACI Committee 350,1990$)$. The concrete stress-strain relationship and the yield strength of Grade 60 reinforcement given in ACI 318-89 are adopted (ACI 1989). Also, the load factors bear a closer resemblance to ACI 318-89 (hereafter referred to as ACI 318 or simply ACI) and are modifled by a "Hydraulic 
Structural Factor," $\mathrm{H}_{\mathrm{f}}$, to account for the serviceability needs of hydraulic structures.

\section{Objective}

4. The primary objective of this study was to develop a desirable strength design procedure for the design of the Corps' reinforced concrete hydraulic structures. A desirable procedure is one which incorporates the standard nomenclature and fundamental procedures used in ACI 318 while accounting for the serviceability requirements of hydraulic structures. Additionally, a desirable procedure is one that eliminates over conservatism and leads to the design of economical structures.

\section{Scope}

5. The study paralleled an effort of the Corps to publish an engineer manual on the SD of RCHS. The interaction of the authors with the task group responsible for writing the engineer manual helped to define the scope for this study.

6. The primary areas of interest pertained to (1) the establishment of a simple factor to be applied to the ACI 318 design equations to ensure serviceability and (2) the establishment of reinforcement ratio limits to improve economy. Parametric studies were conducted to investigate these issues. These studies are discussed in this report along with some related topics. Not all topics addressed by the task group responsible for preparing the new engineer manual are discussed since some are straightforward and will be well documented in the engineer manual. 


\section{PART II: DISCUSSION OF RESEARCH}

\section{Reinforcing Bars - Availability}

7. ETL 1110-2-312 (Headquarters, Department of the Army 1988) specifically refers to the use of Grade 40 and Grade 60 reinforcing bars. A consideration of the availability of these grades of steel is warranted. It is not desirable to allow the use of a particular grade of reinforcement in the design phase if contractors are unwilling or not able to obtain that grade of steel during construction. Such a situation results in a short-notice redesign or postponement of the project.

8. The ACI Committee 439 (ACI 1989) gives a discussion of the physical properties and availability of steel reinforcement in the United States. This current assessment of availability points out that reinforcing bars rolled to the American Society for Testing and Materials (ASTM) A 615 (1987) specification for billet-steel are the most commonly specified and are available throughout the country. In general, the $60 \mathrm{ft}^{*}$ length is the standard length available from most producers without special order. Rail-steel and axlesteel bars are not generally available in most areas of the country. The majority of construction uses billet-steel bars.

9. The ACI Committee 439 states that ASTM A 615 Grade 40 bars in sizes No. 3 through No. 6 and Grade 60 bars in sizes No. 3 through No. 11 are readily available in lengths up to $60 \mathrm{ft}$ in all parts of the country. Bar sizes No. 7 through No. 11 in Grade 40 were deleted in the 1981 edition of ASTM A 615. Grade 60 bars in sizes No. 14 and No. 18 are generally available, but are not usually kept in a fabricator's inventory.

10. The 1987 edition of ASTM A 615 includes provisions for Grade 75 reinforcing bars in sizes Nos. 11, 14, and 18. Grade 75 steel has not been included in ASTM A 615 since it was deleted in the 1974 edition. Since the Grade 75 material was recently reinstated in ASTM A 615, there is currently not enough information to allow the determination of demand and availability.

11. The main thrust of this report is related to improving economy in the design of the Corps reinforced concrete hydraulic structures. Attention will not be given to the use of Grade 75 reinforcing bars, but rather to the

- A table of factors for converting non-SI units of measurement to SI (metric) units is presented on page 3. 
design limitations for Grade 40 and Grade 60 material. The deletion of Grade 40 bar sizes No. 7 through No. 11 since 1981 and the recent reinstatement of some Grade 75 material indicate that the trend of practice is away from Grade 40 material. A mixture of Grade 40 and Grade 60 within a project (although in different components of the structure) will lead to confusion for both the designer and the contractor. If the current trend continues, practically no use of Grade 40 reinforcing bars will be feasible. Although nearfuture revisions of ETL 1110-2-312, such as the new engineer manual, might include reminders of the current availability and specifications regarding Grade 40 bars, the situation should be continually monitored for later revisions.

\section{Crack Control}

12. Liu (1980) states that the control of cracking in reinforced concrete hydraulic structures is particularly important. Structures designed by the working-stress method have low concrete and steel stresses and limited flexural cracking. Two major limitations that are required by ETL 1110-2-312 (hereafter referred to as ETL) for crack control are a maximum reinforcement spacing of $12 \mathrm{in.}$ and the use of $\mathrm{f}_{\mathrm{y}}$ equal to $48 \mathrm{ksi}$ for Grade 60 reinforcement.

13. ACI 318 (1989) presents criterion for flexural reinforcement distribution, based on Gergely and Lutz (1968), for beams and one-way slabs when the value of $f_{y}$ for tension reinforcement exceeds 40,000 psi. The major parameters are:

a. Steel stress, $f_{s}$ (large $f_{s}$ generally corresponds to larger cracks)

b. Concrete cover (thicker cover generally corresponds to larger cracks)

c. Distribution of reinforcement (larger bars result in larger bar spacing and larger cracks)

Section 10.6.5 of ACI states that this criterion may not be sufficient for structures subject to very aggressive exposure or designed to be watertight. For such structures, special investigations and precautions are required; however, ACI does not give further discussion in regard to the special investigations and precautions. The ACI criterion consists of the following expression: 


$$
z=f_{i} \sqrt[3]{d^{A}}
$$

where

$$
\text { Z - a quantity proportional to crack width }
$$

$f_{\text {s }}$ - tensile steel stress, ksi

$d_{c}$ - distance from tension face to centroid of main layer of tension steel, in.

A - parameter accounting for number of principal tension reinforcing bars.

Z shall not exceed $175 \mathrm{k} / \mathrm{in}$. for interior exposure and $145 \mathrm{k} / \mathrm{in}$. for exterior exposure. The $\mathrm{z}$-values of $175 \mathrm{k} / \mathrm{in}$. and $145 \mathrm{k} / \mathrm{in}$. correspond to limiting crack widths of 0.016 and $0.013 \mathrm{in.}$, respectively.

14. ACI 350R-89 (1990) (hereafter referred to as ACI 350 or ACI Sanitary) presents recommendations for structural design, materials, and construction of concrete tanks, reservoirs, and other structures commonly used in water and wastewater treatment works where dense impermeable concrete with high resistance to chemical attack is required. Special emphasis is placed on a structural design which minimizes the possibility of cracking and accommodates vibrating equipment and other special loads. ACI 350 states that sanitary engineering structures must be designed to minimize leakage, and that design methods based on ultimate strength or working stress theories may be used.

15. ACI 350 recommends the concept of sanitary durability coefficients for strength design and states that the coefficients provide conservative service load stresses with Grade 60 steel. The coefficients were selected to provide crack control equivalent to that obtained with working stress design. Watertightness is assumed to be reasonably assured if:

a. The concrete is well compacted.

b. Crack width is minimized.

c. Joints are properly designed and constructed.

d. Impervious linings are used where required.

e. Adequate reinforcing steel is provided.

Usually it is more economical and dependable to resist liquid permeation through the use of quality concrete and proper design of joint details rather than by means of an impervious barrier.

16. ACI 350 states that cracking can be held to a minimum by proper design, reinforcement distribution, and spacing of joints. It is preferable 
to use a larger number of small diameter bars for main reinforcement rather than equal area of larger bars. A maximum bar spacing of $12 \mathrm{in.}$ is recommended. Maximum allowable Z-values for sanitary structures are lower than those given in ACI. Table 1 presents $Z$-values and maximum stress levels at service load. The maximum Z-values of 115 and 95 for normal and severe exposure, respectively, indicate the emphasis on crack control as compared to a maximum $Z$-value of 145 allowed by ACI for exterior exposure.

17. For SD, the previously mentioned sanitary durability coefficients are recommended by ACI 350, and serviceability requirements of ACI to control calculated deflections and crack width are applicable to sanitary structures. However, the $\mathrm{Z}$-values of Table 1 are to be used as maximum values, and service load stresses may be taken as $f_{\mathrm{s}}$ equal to $25 \mathrm{ksi}$ to determine values of $\mathrm{Z}$ for bar spacings up to $12 \mathrm{in.}$ The $\mathrm{Z}$-values were established for cover not to exceed 2 in. Additional cover is regarded as added protection.

18. It is interesting to note that the Gergely-Lutz criterion used by ACI and ACI 350 does not directly involve the value of $f_{y}$. The criterion was developed for when $f_{y}$ exceeds $40 \mathrm{ksi}$. The use of $f_{y}$ equal to $48 \mathrm{ksi}$ (ETL) or $60 \mathrm{ksi}$ (ACI and ACI 350) for Grade 60 reinforcement does not affect the computation of $\mathrm{Z}$, particularly for the criterion of ACI 350 where $f_{8}$ may be taken as $25 \mathrm{ksi}$.

19. It is obvious that the ETL limit of $\mathrm{f}_{\mathrm{y}}$ equal to $48 \mathrm{ksi}$ will help to minimize cracking by limiting the stresses in the tension reinforcement and concrete. It appears that the limit of $f_{y}$ equal to $48 \mathrm{ksi}$ will not be necessary if the ACI 350 criterion (Z-values) is adopted. More study on the effects of using the ACI 350 criterion for crack control on the design and cost of the Corps' structures is needed.

20. The load factors of ACI are to be applied directly to sanitary structures and the total factored design load (U) increased by the sanitary durability coefficients. The load factors for both the lateral earth pressure and the lateral liquid pressure are taken as 1.7. The sanitary durability coefficients are as follows:

a. In calculations for reinforcement in flexure, the required strength should be $1.3 \mathrm{U}$.

b. In calculations for reinforcement in direct tension, the required strength should be $1.65 \mathrm{U}$. 
Table 1

Recommended Stresses at Service Load for Recommended Maximum

12-in. Spacing Reinforcing Bars in Sanitary Structures

(after ACI 350R-89 (1990))

\begin{tabular}{|c|c|c|c|c|c|}
\hline \multirow{2}{*}{$\begin{array}{l}\text { Bar } \\
\text { Sizes } \\
\end{array}$} & \multirow{2}{*}{$\begin{array}{c}\text { Sanitary Structure Exposure } \\
\text { Condition* and } \\
\text { Maximum Z-Value** } \\
\end{array}$} & \multicolumn{4}{|c|}{$\begin{array}{c}\text { Maximum Stress at Service } \\
\text { Load, psi }\end{array}$} \\
\hline & & Grade & 60 & Grade & \\
\hline All sizes & Members in direct tension & $\begin{array}{r}14,000 \\
(96,000\end{array}$ & $\mathrm{kPa})$ & $\begin{array}{r}14,00 \\
(96,000\end{array}$ & $\mathrm{kPa})$ \\
\hline \multirow{2}{*}{$\underset{5}{\operatorname{Nos} .3,4 \text {, and }}$} & $\begin{array}{l}\text { Flexural members } \\
\text { Severe exposure } \\
\text { (Maximum } Z-95 \text { ) }\end{array}$ & $\begin{array}{r}22,000 \\
(152,000\end{array}$ & $\mathbf{k P a})$ & $\begin{array}{r}20,000 \\
(138,000\end{array}$ & $\mathrm{kPa})$ \\
\hline & $\begin{array}{l}\text { Flexural members } \\
\text { Normal sanitary exposure } \\
\text { (Maximum } \mathrm{Z}=115 \text { ) }\end{array}$ & $\begin{array}{r}27,000 \\
(186,000\end{array}$ & $\mathbf{k P a})$ & $\begin{array}{r}20,000 \\
(138,000\end{array}$ & $\mathrm{kPa})$ \\
\hline \multirow[b]{2}{*}{$\underset{8}{\text { Nos. } 6,7 \text {, and }}$} & $\begin{array}{l}\text { Flexural members } \\
\text { Severe exposure } \\
\text { (Maximum } Z \text { - 95) }\end{array}$ & $\begin{array}{r}18,000 \\
(124,000\end{array}$ & $\mathbf{k P a})$ & $\begin{array}{r}18,000 \\
(124,000\end{array}$ & $\mathbf{k P a})$ \\
\hline & $\begin{array}{l}\text { Flexural members } \\
\text { Normal sanitary exposure } \\
\text { (Maximum } \mathrm{Z}=115 \text { ) }\end{array}$ & $\begin{array}{r}22,000 \\
(152,000\end{array}$ & $\mathrm{kPa})$ & $\begin{array}{r}20,000 \\
(138,000\end{array}$ & $\mathrm{kPa}$ ) \\
\hline \multirow[b]{2}{*}{$\begin{array}{l}\text { Nos. } 9,10, \text { and } \\
11\end{array}$} & $\begin{array}{l}\text { Flexural members } \\
\text { Severe exposure } \\
\text { (Maximum } Z=95 \text { ) }\end{array}$ & $\begin{array}{r}17,000 \\
(117,000\end{array}$ & $\mathbf{k P a})$ & $\begin{array}{r}17,000 \\
(117,000\end{array}$ & $\mathbf{k P a})$ \\
\hline & $\begin{array}{l}\text { Flexural members } \\
\text { Normal sanitary exposure } \\
\text { (Maximum Z - 115) }\end{array}$ & $\begin{array}{r}21,000 \\
(145,000\end{array}$ & $\mathrm{kPa}$ ) & $\begin{array}{r}20,000 \\
(138,000 \\
\end{array}$ & $\mathrm{kPa})$ \\
\hline
\end{tabular}

* Normal sanitary exposure is defined as liquid retention (watertight), exposure to liquids with $\mathrm{pH}>5$ or exposure to sulfate solutions of less than 1,500 ppm. Severe sanitary exposures are conditions in which the limits defining normal sanitary exposures are exceeded.

** The Z-values referred to are defined in ACI 318. Derivation for crack control formulas are in the commentary to ACI $318 \mathrm{R}$.

c. In calculations for reinforcement in diagonal tension (shear), the required strength should be 1.3 times the excess of applied shear $\mathrm{V}_{\mathrm{u}}$ less shear carried by the concrete $\phi \mathrm{V}_{\mathrm{c}}\left[1.3\left(\mathrm{~V}_{\mathrm{u}}-\mathrm{V}_{\mathrm{c}}\right) \leq \phi \mathrm{V}_{\mathrm{s}}\right]$ where $\phi V_{s}$ is the design capacity of the shear reinforcement.

d. In calculations for the compressive region of flexure and compressive axial loads, and for all loads carried by concrete, the required strength should be $1.00 \mathrm{U}$. 
The durability coefficients were developed from crack width calculation methods. Such methods are not significant for walls less than $10 \mathrm{in.} \mathrm{thick} \mathrm{and}$ with one layer of reinforcement placed at midthickness of the wall.

21. The effects of $f_{y}=48 \mathrm{ksi}$ versus $60 \mathrm{ksi}$ for Grade 60 reinforcement will be discussed further in the following section. The application of the sanitary durability coefficients will also be discussed.

\section{Section Strength}

22. The ultimate strength design criteria presented in the ETL was developed to yield designs equivalent to the working stress method. The major differences between the ETL and the ACI criteria are the values of the parameters shown in Table 2 .

Table 2

\section{Primary Parameters}

\begin{tabular}{|c|c|c|}
\hline Parameter & ETL & $\begin{array}{l}\text { ACI } \\
\end{array}$ \\
\hline B & $\begin{array}{l}0.55 \text { for } f_{c}^{\prime}<4.0 \mathrm{ksi} \\
0.50 \text { for } f_{c}^{\prime}>4.0 \mathrm{ksi}\end{array}$ & $\begin{array}{l}0.85 \text { for } f_{c}^{\prime}<4.0 \mathrm{ksi} \\
0.85-0.5\left(f_{c}^{\prime}-4.0\right) \text { for } f_{c}^{\prime}<4.0 \mathrm{ksi} \\
\text { but not less than } 0.65\end{array}$ \\
\hline$\epsilon_{\mathrm{cmax}}$ & 0.0015 & 0.003 \\
\hline$P_{\max F}$ & 0.7 & 0.8 \\
\hline$\rho_{\max }$ & $0.25 \rho_{b}$ & $0.75 \rho_{b}$ \\
\hline$f_{y}$ & $\begin{array}{l}40 \mathrm{ksi} \text { for Grade } 40 \\
48 \mathrm{ksi} \text { for Grade } 60\end{array}$ & $\begin{array}{l}\text { ksi for Grade } 40 \\
\text { ksi for Grade } 60\end{array}$ \\
\hline
\end{tabular}

Notes: $\quad B=$ depth of stress block as a fraction of the depth of compressive face.

$\epsilon_{\text {cmex }}=$ maximum allowable concrete strain.

$\mathrm{P}_{\max }$ - factor limiting strength due to axial load.

$\rho_{\max }=$ maximum allowable reinforcement ratio given as fraction of balance ratio, $\rho_{b}$.

$f_{y}=$ yield strength of reinforcement.

23. The parameters $B, \epsilon_{c \max }$, and $f_{y}$ are the primary parameters affecting the computed strength of a section. The parameter $P_{\max }$ applies only to the region approaching pure axial compression, and $\rho_{\max }$ simply limits the amount of steel that the designer may use. Although the limit $\rho_{\max }$ is important, it 
does not directly affect the computation of section strength and is discussed elsewhere. The difference between the values of $B$ in the ETL and ACI criteria is actually a result of the $\epsilon_{\text {cmax }}$ values being different. Therefore, the most significant differences in the ETL and ACI criteria for computing the strength of a section are the values of $\epsilon_{c \max }$ and $f_{y}$.

24. To aid in the study of the ETL and ACI criteria, the strength of the section shown in Figure 1 (Liu 1981) is investigated. The computer program CSTR (Hamby and Price 1984) was used to aid in the development of the nominal strength design interaction diagrams presented in this discussion. The curves were digitized to allow file manipulation for comparative plots of interaction diagrams. Also, some plots to be discussed later are the results of applying particular factors to the basic diagrams. Since the diagrams were digitized by hand with a personal computer, the curves are not perfectly smooth but are sufficiently accurate for this study.

25. Figures 2 and 3 represent the nominal strength curves with the parameter $P_{\max F}$ equal to 1.0 and $f_{y}$ varied for the ETL and ACI methods, respectively. As expected, the primary effect of an increase in $f_{y}$ is an increase in strength in the region of tension failure (below the balance point) for both the ETL and the ACI diagrams. The greatest effect of $f_{y}$ is for the case of pure bending (no axial load) where an $f_{y}$ of $60 \mathrm{ksi}$ results in a moment capacity over 20 percent greater than that corresponding to an $f_{y}$ of 48 ksi for both Figures 2 and 3 . This is one of the effects of limiting $f_{y}$ to 48 ksi for Grade 60 reinforcement in the ETL.

26. Figures 4,5 , and 6 make a direct comparison of the ETL and ACI curves for $f_{y}$ equal to 40,48 , and $60 \mathrm{ksi}$, respectively. In each case, the ETL and ACI curves are identical up to the ETL balance point. Beyond the balance point, the ACI curves correspond to strength (moment capacity) values up to over 25 percent greater than that of the ETL. The difference diminishes at the higher axial loads.

27. As discussed in the Crack Control section of this report, the ACI 350 (Sanitary) durability coefficients require an increase in the required strength (1.3U) in the region below the balance point. Above the balance point, the required strength remains at $1.0 \mathrm{U}$. Since the axial-load/moment interaction diagrams may be thought of as failure curves, a division of the coordinates of points on the ACI curves by 1.3 in the region below the balance point will reflect the effect of the sanitary durability coefficients. Figures 7, 8, and 9 compare the ETL, ACI, and ACI Sanitary curves for $f_{y}$ equal 
to 40,48 , and $60 \mathrm{ksi}$, respectively. Figures 7,8 , and 9 indicate that the ACI Sanitary criterion is more conservative than that of the ETL for values below the balance point and vice versa above the balance point. However, these figures do not reflect the effect of different load factors required by each method. The ETL allows the use of a single load factor for both dead and live load. The ACI and ACI Sanitary essentially require a factor of 1.4 for dead load and 1.7 for live load.

28. It is difficult for comparative purposes, to determine exactly the value of an equivalent single load factor for ACI and ACI Sanitary. The lower the load factor, then the less conservative will be the interaction curve. Figure 10 was developed with consideration of the load factor parameter for when $f_{y}$ equal to $40 \mathrm{ksi}$. Since 1.4 and 1.7 are the lower and upper bound load factors, respectively, they are reflected in Figure 10. A load factor of 1.9 is assumed for the ETL curve; therefore, the ACI Sanitary curve of Figure 7 was multiplied by $1.9 / 1.4$ and $1.9 / 1.7$ for the load factors of 1.4 and 1.7 , respectively.

29. The actual values of moment and axial load given in Figure 10 have practically no meaning in this comparison. The relative positions of the curves are being studied. For $f_{y}$ equal to $40 \mathrm{ksi}$, Figure 10 indicates that the ETL is more conservative than ACI and ACI Sanitary in practically all regions above the balance point. Figure 10 also indicates that the ACI Sanitary criterion is more conservative than the ETL in the region below the ETL balance point for nearly all values of load factor from 1.4 to 1.7 (except for load factors near 1.4). Figure 10 indicates that ACI Sanitary is not as conservative when the dead load is large compared to the live load. A significant amount of dead load results in a load factor approaching 1.4, whereas a large percentage of live load will result in a load factor approaching 1.7.

30. As in previous figures, Figure 10 shows that the ETL balance point occurs at an axial load significantly less than that of the ACI balance point. Although Figure 10 does not show the effect of load factors on the ACI curve, it can be visualized since the ACI and ACI Sanitary curves are identical above the balance point. The ACI curve does not have a discontinuity at the balance point. Therefore, the curves showing the effect of load factors (1.4 and 1.7) on ACI Sanitary will continue as smooth curves below the balance point to reflect the effect of load factors on ACI. This indicates that the ETL is considerably more conservative than ACI at all values of moment and axial 
load. The greatest difference between the ETL and ACI curves (with or without load factor effects) is the region above the ETL balance point.

31. As previously mentioned and as demonstrated in Figure 10, the ACI Sanitary curve is identical to the ACI curve in the region above the balance point. In other words, ACI 350 does not call for a reduction in strength or an increase in load to minimize cracking in the region above the balance point. In contrast, the ETL criteria does not differentiate between the compression control and tension control regions for crack control and serviceability. The ACI Sanitary approach has some validity because tensile cracking is more likely to occur in the region below the balance point. This is evident from the definition of the balance point.

32. Although it seems reasonable that, in order to improve economy in design, less conservatism should be induced for the region above the balance point than for below, it is not clear what degree of conservatism should be applied in each region. The correlation between the ETL and the ACI Sanitary curves for $f_{y}$ equal to $40 \mathrm{ksi}$ is quite good for load factors around $1.4 \mathrm{in}$ the region below the balance point.

33. An interesting observation from Figure 10 is that a load factor of 1.9 above the balance point (as demonstrated by the curve labeled simply as "ACI Sanitary") combined with a load factor near 1.4 below the balance point results in a relatively smooth curve. Figure 10 indicates that the use of the ACI Sanitary criterion, even for most usages when load factors are considered, increases conservatism beyond that of the ETL for the region below the balance point. The purpose of this study is to investigate methods to increase economy in the Corps' structural designs. With this goal in mind, it is observed from Figure 10 that use of the ACI Sanitary criterion (with load factors between 1.4 and 1.7) will allow some increase in economy for sections with load paths falling in the region between the ETL and the ACI balance points. However, the increase in conservatism below the balance point is undesirable. The use of the ACI criterion with a load factor of 1.9 results in a curve which follows the ETL curve up to the ETL balance point and then falls between the ACI Sanitary curves for load factors of 1.4 and 1.7 until the ACI balance point is reached. Just above the ACI balance point, the ACI and ACI Sanitary curves are identical for a load factor of 1.9 and reflect increased economy over the ETL criterion in this region (where it seems reasonable to give some credit to the enhancements of compressive axial load). For higher axial loads, the ETL and ACI criteria yield essentially identical curves. 
Therefore, it appears that the ACI criterion with the load factor criterion of the ETL may be the most appropriate criterion for further consideration by the Corps for Grade 40 reinforcement.

34. Although it is reasonable to consider the compressive load enhancement in the region above the ACI balance point as recognized by ACI 350 , it is conservative to apply some reduction to this enhancement. For example, Figure 11 indicates the results of varying the maximum allowable concrete strain from 0.0015 to 0.003 . The parameter, $B$, was maintained at 0.85 . This variation only slightly affects the ACI curve, with most of the effect occurring just above the balance point. However, the use of the ACI criterion with a maximum concrete strain of 0.0015 to 0.002 will allow a significant increase in economy over the ETL criterion while adding some conservatism to the ACI Sanitary criterion in this region (since ACI and ACI Sanitary are identical above the balance point).

35. Although the ETL and ACI criteria each assume a value of $f_{y}$ equal to $40 \mathrm{ksi}$ for Grade 40 reinforcement, they require different values of $f_{y}$ for Grade 60 reinforcement. This difference complicates the conclusions derived from Figure 10. Figure 12 presents a comparison similar to Figure 10 except that Grade 60 reinforcement is assumed. Again, the ETL, ACI, and ACI Sanitary curves are assumed to represent the results of having a single load factor of 1.9. Two additional curves are given to reflect the load factors of 1.4 and 1.7 for the ACI Sanitary criterion.

36. Figure 12 shows that the ACI Sanitary criterion is only slightly more conservative than that of the ETL in the region below the ETL balance point, and Figure 10 shows that the ACI Sanitary criterion is considerably more conservative than that of the ETL for Grade 40 reinforcement. The consideration of load factors (1.4 and 1.7) in Figure 12 indicates that the ACI Sanitary criterion is considerably less conservative than that of the ETL for the region below the balance point, except for loading conditions where the live load is large compared to the dead load. Figure 12 indicates that the ACI Sanitary criterion with a load factor of 1.9 is similar to the ETL criterion below the balance point, but will improve the economy of structures in the region above the balance point, until the region of large axial loads where the criteria give similar values. Similarly, the use of a load factor of 1.7 provides a good match below the balance point, but the curve deviates from the ETL curve above the balance point. As previously discussed, the axial compressive loads above the balance point are assumed to contribute to 
crack control. Figure 13 is similar to Figure 11 in that the use of a maximum concrete strain of 0.0015 to 0.002 will induce some conservation to the ACI criterion and economy in designs as compared to the ETL criteria.

37. Figure 10 indicates that the improved strength design criterion should perhaps consist of the ACI 318 criterion with the ETL load factor when Grade 40 reinforcement is used. Figure 12 indicates that the ACI Sanitary criterion with the ETL load factor, or with a load factor of 1.7 , is more appropriate for Grade 60 reinforcement. The only difference in these two proposed criteria is that the sanitary durability coefficient of 1.3 will be applied to the region below the balance point for Grade 60 reinforcement. This improved strength criterion will closely follow the ETL criterion in the region below the balance point, but will result in more economical designs in the region just above the balance point. A desirable fact concerning this criterion is that it employs the ACI values for all design parameters. Engineers are experienced and comfortable with the ACI procedure.

38. Since the ETL and the ACI Sanitary criteria were developed to give designs equivalent to that of the working stress method, a comparison with the working stress method is appropriate and will be discussed in the following section.

\section{Comparison with Working Stress Method}

39. As mentioned previously, the ETL strength design criterion was developed to yield designs equivalent to the working stress method. Of course, one should not expect a perfect correlation between the ETL and working stress methods. Engineer Manual 1110-1-2101, dated 1 November 1963, presents criteria for working stress design. It states that for hydraulic structures concrete which will be subjected to submergence, wave action, spray, exposure to chemically contaminated atmosphere and severe climatic conditions will be designed with working stresses in accordance with the ACI Building code. The allowable stresses given in EM 1110-1-2101 are as follow:

a. Flexure $\left(f_{c}\right)$ :

Extreme fiber stress in compression............ $0.35 \mathrm{f}^{\prime}$ c

Extreme fiber stress in tension (plain concrete for footings, walls, and on down stream toe of spillway weirs but not for other portions of gravity section) $\ldots \ldots \ldots \ldots \ldots \ldots \ldots 1.2 \mathrm{f}^{\prime}$. 
Extreme fiber stress in tension (for other portions of

gravity sections where permitted by the pertinent

engineering manual) $\ldots \ldots \ldots \ldots \ldots \ldots \ldots \ldots \ldots \ldots \ldots \ldots \ldots \ldots \ldots$

b. Types of structures to which these modifications apply are:

Stilling basin slabs and walls

Concrete-lined channels

Portions of powerhouses

Spillway piers

Spray walls and training walls

Flood walls

Intake and outlet structures below maximum high water and wave action

Lock walls, guide, and guard walls

Retaining walls subject to contact with water.

Allowable stress in reinforcement will be in accordance with the ACI Building Code except for tension in deformed bars with a yield strength of 60,000 psi or more, the stress $\left(f_{8}\right)$ shall not exceed 20,000 psi.

40. At the time of publication of EM 1110-1-2101, the ACI Building Code allowed a compressive stress of $0.45 \mathrm{f}_{\mathrm{c}}$ in the extreme fiber of concrete. For reinforcement in tension, a stress of 20,000 psi was allowed. In compression, the allowable stresses in reinforcement was equal to 20,000 psi and 24,000 psi for Grade 40 and Grade 60 reinforcement, respectively.

41. The approach given by Everard (1969) was used to determine the allowable service load capacities (working stress interaction diagram) for the section of Figure 1. Figures 14 through 19 compare the ETL, ACI, and ACI Sanitary criteria with the working stress method for $f_{c}$ equal to $0.35 f^{\prime}$, $f_{8}$ equal to $20 \mathrm{ksi}$, and $f_{s}$ equal to $24 \mathrm{ksi}$. The strength reduction factor $\phi$ is taken as 0.7 . The ETL follows ACI 318 criteria for determining $\phi$ values as given below:

a. Flexure, without axial load, - -0.90. Axial load and axial load with flexure. (For axial load with flexure, both axial load and moment nominal strength shall be multiplied by appropriate single value of $\phi$ ):

(1) Axial tension and axial tension with flexure--0.90.

(2) Axial compression and axial compression with flexure (Members with spiral reinforcement conforming to Section 10.9.3) $=0.75$. 
b. Other reinforced members--0.70, except that for low values of axial compression $\phi$ may be increased in accordance with the following:

(1) For members in which $f_{y}$ does not exceed 60,000 psi, with symmetric reinforcement, and with $\left(h-d^{\prime}-d_{s}\right) / h$ not less than $0.70, \phi$ may be increased linearly to 0.90 as $\phi P_{n}$ decreases from $0.10 f^{\prime}{ }_{c} A_{g}$ to zero.

(2) For other reinforced members, $\phi$ may be increased linearly to 0.90 as $\phi \mathrm{P}_{\mathrm{n}}$ decreases from $0.10 \mathrm{f}^{\prime}{ }_{c} \mathrm{~A}_{\mathrm{g}}$ or $\phi \mathrm{P}_{\mathrm{b}}$, whichever is smaller, to zero.

42. For simplification, Figures 14 through 19 do not account for the allowed increase in $\phi$ at low axial loads, and $\phi$ is taken as 0.7 for all points, even pure flexure. Figures 20 through 25 correspond to Figures 14 through 19, respectively, in that the only parameter having a different value is $\phi$ being changed to 0.9 . This reflects the effect of $\phi$ and gives the correct value for the point of moment with no axial load. Although curves are given for $f_{y}$ equal to 40,48 , and $60 \mathrm{ksi}$ in each of Figures 14 through 25 , only $f_{y}$ equal to $40 \mathrm{ksi}$ is appropriate when $f_{s}$ equal to $20 \mathrm{ksi}$, and $f_{y}$ equal to $60 \mathrm{ksi}$ is appropriate for $\mathrm{f}_{\mathrm{s}}$ equal to $24 \mathrm{ksi}$.

43. Figure 14 shows that the ETL is within the ACI working stress criteria ( $f_{c}$ equal to $0.45 f^{\prime}{ }_{c}$ ) in all regions for $f_{y}$ equals to 40 and $48 \mathrm{ksi}$ with $f_{8}$ equal to $20 \mathrm{ksi}$. The ETL curves in Figure 14 were developed by multiplying the values of points on the nominal strength curves of Figure 2 by $\phi$ and dividing by the load factor of 1.9, resulting in service load curves. As expected, the ETL curves do not perfectly fit the EM 1110-1-2101 working stress criteria ( $f_{c}$ equal to $0.35 f^{\prime}{ }_{c}$ ) but are reasonably close. All three ETL curves are outside the $f_{c}$ equal to $0.35 \mathrm{f}^{\prime}{ }_{c}$ curve at the balance point and for most of the region above the balance point. Only the ETL curve with $f_{y}$ equal to $60 \mathrm{ksi}$ falls outside the working stress curve at the point of zero axial load. However, Figure 20 (with $\phi$ equal to 0.9 ) shows that only the ETL curve with $f_{y}$ equal to $40 \mathrm{ksi}$ is near the working stress curve for zero axial load. The application of $\phi$ equal to 0.9 to the entire ETL curve (as in Figure 20) is actually not appropriate, except that it shows the significant effect of $\phi$. A $\phi$-value of 0.9 puts the ETL curves outside even the ACI working stress criteria for most regions.

44. Figure 15 differs from Figure 14 only in that a value of $f_{s}$ equal to $24 \mathrm{ksi}$ is used for the working stress curves. Actually, only the ACI criteria allows $f_{\mathrm{s}}$ equal to $24 \mathrm{ksi}$, and that is only for $f_{\mathrm{y}}$ equal to $60 \mathrm{ksi}$. The primary observation from Figure 15 is that the $f_{y}$ equal to $60 \mathrm{ksi}$ curve falls 
within the ACI ( $f_{c}$ equal to $0.45 f^{\prime}{ }_{c}$ ) working stress curve. However, Figure 21 (with $\phi$ equal to 0.9 ) shows that the zero axial load point is still significantly outside the working stress curves.

45. Figure 16 shows that the ACI strength design curve with $f_{y}$ equal to $40 \mathrm{ksi}$ fits the working stress criteria ( $f_{c}$ equal to $0.45 f^{\prime}{ }_{c}$ ) quite well in the region near and below the balance point. This is consistent with the observations in the previous section on section strength. Figure 22 shows that this is even true when $\phi$ equal to 0.9 at zero axial load for $f_{y}$ equal to $40 \mathrm{ksi}$. Figure 16 shows that the strength curve is outside the working stress curve only in the region just around the balance point. It must be remembered that a load factor of 1.9 is used for the comparison given in Figure 16 . As shown in Figure 10, the actual load factor between 1.4 and 1.7 for ACI will move the ACI curves out (increase moment and axial load values) considerably.

46. Figures 17 and 23 are applicable for $f_{y}$ equal to $60 \mathrm{ksi}$. Although Figure 17 shows a good fit for $f_{y}$ equal to $60 \mathrm{ksi}$, Figure 23 reveals that the zero axial load point is considerably outside the working stress curve.

47. Figure 18 (ACI Sanitary) differs from Figure 16 (ACI) only in the regions below the balance points of the strength curves. The conservatism of the ACI Sanitary criteria is reflected in this region, and Figure 24 shows that the $f_{y}$ equal to $40 \mathrm{ksi}$ curve is well within the working stress criteria ( $f_{c}$ equal to $0.45 f^{\prime}{ }_{c}$ ). A load factor of 1.9 was also used in developing these curves.

48. Similar to Figures 18 and 24 for $f_{y}$ equal to $40 \mathrm{ksi}$, Figures 19 and 25 show that the ACI Sanitary curve for $f_{y}$ equal to $60 \mathrm{ksi}$ is well within the $f_{c}$ equal to $0.45 f^{\prime}$ c curve at nearly all locations.

49. Of primary interest in this study are the comparisons of the ETL and ACI Sanitary curves with the EM 1110-1-2101 ( $f_{c}$ equal to $0.35 f^{\prime}{ }_{c}$ ) curves. As shown in Figure 7, Figures 14 and 18 show that the ACI Sanitary curves are more conservative than the ETL curves for the region below the balance point. However, the ETL curve for $f_{y}$ equal to $48 \mathrm{ksi}$ and the ACI Sanitary curve for $f_{y}$ equal to $60 \mathrm{ksi}$ are very similar in the region of small axial load. This is consistent with the observations in the previous discussion on section strength. Actually, this observation is more appropriate for Figures 15 and 19, which are for Grade 60 reinforcement. Figures 20 and 24 ( $\phi$ equal to 0.9 ) show that the ACI Sanitary curves ( $f_{y}$ equal to 40 and $48 \mathrm{ksi}$ ) are within the $f_{c}$ equal to $0.35 \mathrm{f}^{\prime} \mathrm{c}$ curve at zero axial load, but the ETL curves are not. 
50. Figures 14 and 18 show that both the ETL and ACI Sanitary curves are out de the EM 1110-1-2101 criteria for most of the region above the balance $;$ int. The ACI Sanitary curves are further outside the working stress curve in this region as was shown in Figure 7.

\section{Effects of $\rho_{\max }$ on Cost and Constructibility}

51. A study was conducted to determine the sensitivity of the cost of reinforced concrete members to the ratio $\rho_{\max }$. The value of $\rho_{\max }$ was varied through the set $0.25,0.375,0.5$, and $0.75 \rho_{\mathrm{b}}$. The concrete stress block parameters given in ACI 318 were used. Constructibility considerations were:

a. Bottom cover over reinforcing equal to 3 in. clear plus 0.5 in. equal to $3-1 / 2$ in. to bar center.

b. Bar spacings of

(1) Two No. 11 maximum bar size at $6 \mathrm{in.}$ in thin sections

(2) Four No. 11 maximum bar size at 3 in. unless multiple layers needed

(3) Three No. $18 \mathrm{~S}$ maximum bar size at 4 in. in beams with beam height, $\mathrm{H}, \geq 5 \mathrm{ft}$

c. Layer spacings of 6 in. clear plus $1-1 / 2$ in. bar equal to 7.5 in.

52. For each value of $\rho_{\max }$, the total beam height, $H$, was varied through the set of values ( $4 \mathrm{ft}, 8 \mathrm{ft}$ ). With axial force $P$ equal to 0.0 , and maximum bar size and spacing set to conform to EM 1110-2-2103 for 1.5-in. aggregate, the applied factored moment was increased to the point just below where compressive reinforcement is required. The resulting design was recorded. Then the moment was reduced to the point where one layer of maximum steel was sufficient. The resulting design was compared with the first one.

53. Cost estimates were based on values of $\$ 150$ per cu yd for formed, unreinforced concrete and of $\$ 0.45$ per pound for fabricated and placed reinforcing steel.

54. The variation of moment strength versus $\rho_{\max }$ is shown in Figure 26 . Resulting plots for beam depths with a single layer of reinforcement are shown with a solid line. Selected variations with multiple layers of reinforcement are shown with dotted lines.

55. The variation of estimated construction cost versus $\rho_{\max }$ is shown in Figure 27. Notation and plotting conventions are the same as for Figure 26. 
56. The variation of moment strength, normalized by dividing the moment strength of each plotted design point by the estimated construction cost for the design at that point, is shown in Figure 28. Again, the notation and plotting conventions are the same as for Figure 26. Table 3 shows numerical results of the computer runs and the calculations.

57. For the 4-ft-deep beam, there was essentially no difference in the ratio of strength per dollar as $f_{y}$ was increased from 48 to $60 \mathrm{ksi}$ for $\rho_{\max }$ equal to 0.25 and $0.375 \rho_{\mathrm{b}}$. When $\rho_{\max }$ was increased to 0.5 and $0.75 \rho_{\mathrm{b}}$, the ratio for $f_{y}$ equal to 60 increased noticeably above the ratio for $f_{y}$ equal to 48 , the increase being 14 percent for $\rho_{\max }$ equal to 0.5 and 29 percent for $\rho_{\max }$ equal to 0.75 .

58. For the 8-ft-deep beam and reinforcement limited to one tensile layer, the same pattern of variation occurred. Essentially no difference occurred with $\rho_{\max }$ equal to 0.25 or $0.375 \rho_{\mathrm{b}}$, a difference of 21 percent occurred at $\rho_{\max }$ equal to $0.5 \rho_{\mathrm{b}}$, and a differenced of 23 percent occurred for $\rho_{\max }$ equal to 0.75 . With all of the positive reinforcement that the beam could use with $\rho_{\max }$ equal to 0.75 , without needing negative reinforcement in place, the difference was -208 percent. This pattern exhibited the same behavior (reinforcement dominating the beam behavior, being very inefficient, and therefore costly as it went into many layers approaching the neutral axis) as it exhibited for $f_{y}$ equal to $48 \mathrm{ksi}$.

59. For $\rho_{\max }$ equal to 0.25 and 0.375 , the two yield strengths of 48 and $60 \mathrm{ksi}$ yielded the same ratio of strength to cost. Above this, the increased yield strength produced greater strength for a given cost. Therefore, keeping $\rho_{\max }$ below about 0.4 maintains equivalence for tensile failures with the ETL, regardless of the other parameters.

\section{Effects of $\rho_{\max }$ on Design of a T-Wall}

60. To further study the effects of increasing $\rho_{\max }$ above the ETL limit of $0.25 \rho_{b}$, a parameter study was conducted using an actual 43-ft-tall T-wall recently designed by a Corps district office. The factored applied moment at the base of the stem was $1,751 \mathrm{k}-\mathrm{ft}$. The Corps office used this factored 
Table 3

\section{Strength Versus Cost}

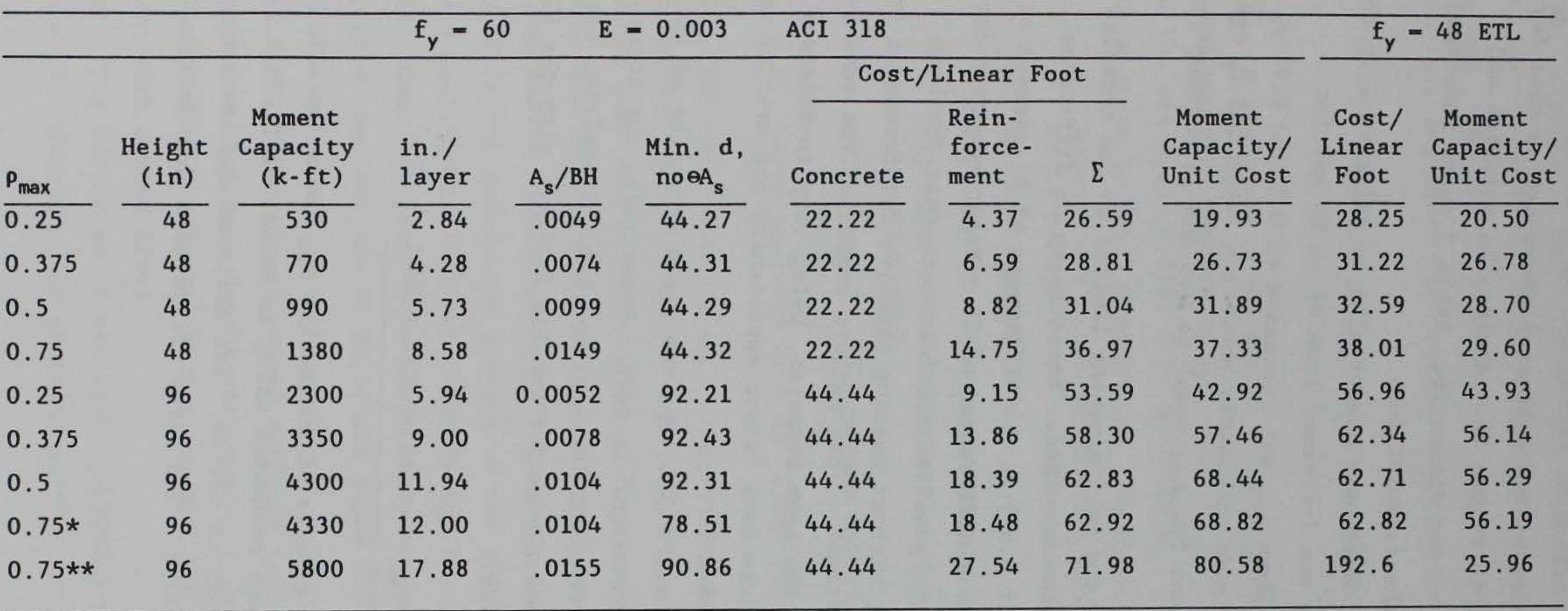

* Limited by maximum steel in one layer for $f_{y}=60$.

** Limited to only positive reinforcement for $f_{y}=60$. 
moment (based on $\mathrm{H}_{f} \times$ load factor of 1.7 ; $\mathrm{f}_{\mathrm{c}}^{\prime}$ equal to $3 \mathrm{ksi}$; $\mathrm{f}_{\mathrm{y}}$ equal to $60 \mathrm{ksi}$ ) to design the wall and developed a 9.3-ft-thick section with a steel ratio of $0.18 \rho_{b}$.

61. From Table 4, it can be seen that if the ETL limit of $\rho_{\max }$ equal to $0.25 \rho_{\mathrm{b}}$ were used, a section about $6.9 \mathrm{ft}$ thick would be adequate. For the ratios of $0.375 \rho_{b}$ and $0.5 \rho_{b}$, the adequate sections are approximately 5.7 and $5.1 \mathrm{ft}$ thick, respectively. Figure 29 gives one a physical feel for these dimensions. The percent increase in thickness above that corresponding to $\rho_{\max }=0.25 \rho_{\mathrm{b}}$ was approximately 17 and 26 percent, respectively, for $\rho_{\max }$ values of $0.375 \rho_{\mathrm{b}}$ and $0.5 \rho_{\mathrm{b}}$. 
Table 4

I-Wall Parameter Study

Thickness at

Base of Stem ft

2

3

4

5

6

7

8

\begin{tabular}{l}
$\frac{\rho_{\max }}{\text { Fraction of } \rho_{\mathrm{b}}}$ \\
\hline 0.25 \\
0.375 \\
0.5 \\
0.75
\end{tabular}

0.25

0.375

0.5

0.75

0.25

0.375

0.5

0.75

0.25

0.375

0.5

0.75

0.25

0.375

0.5

0.75

0.25

0.375

0.5

0.75

0.25

0.375

0.5

0.75
Moment

Capacity $\mathrm{K}-\mathrm{ft}$

129.2

188.7

226.4

322.2

290.6

429.3

528.4

739.5

537.3

797.5

1054.9

1430.2

917.4

1275.9

1710.4

2463.3

1232.6

1919.4

2332.3

3376.5

1837.6

2702.8

3465.4

4656.8

2542.7

3655.2

4407.8

6151.7 


\section{Conclusions}

62. The current trend is toward the elimination of Grade 40 reinforcement in practice. Grade 40 steel in bar sizes No. 5 through 11 may not be available now in many locations.

63. The two most important parameters affecting the computation of section strength are $\epsilon_{\mathrm{cmax}}$ and $\mathrm{f}_{\mathrm{y}}$. A comparison of the nominal strengths (neglecting effects of load and strength-reduction factors) as computed using the ETL and ACI criteria indicates that the ETL is considerably more conservative than the ACI in most of the region above the ETL balance point.

64. For a constant load factor, the consideration of the ACI 350 durability coefficients indicates that the ACI 350 is more conservative than the ETL below the balance point, and vice versa above the balance point, for Grade 40 reinforcement. The ACI 350 criterion does not penalize the section strength in the region above the balance point. This is reflected by a durability coefficient of 1.0. The use of the ACI 318 criterion with the ETL load factors appears to be a desirable approach to increasing economy in the Corps' structural designs for use of Grade 40 reinforcement. This study indicated that the durability coefficients are too conservative for Grade 40 reinforcement, but appear to be appropriate for Grade 60 reinforcement.

65. Comparisons with the working stress design criteria indicate that all of the strength design criteria studied give results that are generally within that given by the ACI working stress criterion in all regions, but outside that of the EM 1110-1-2101 working stress criterion in the regions near the balance point. It is obvious that (even for strength design criteria developed to be equivalent to working stress criteria) the strength design criteria are not as conservative as the working stress criteria for most regions. However, the match is generally good at points of zero moment and zero axial load. The comparisons of the strength design criteria with the working stress design criteria indicate that the conclusions drawn from the study on section strength are reasonable.

66. It appears that the limits on $\rho_{\max }$ may be slightly increased without undesirable consequences as long as attention is given to serviceability and constructibility. Keeping $\rho_{\max }$ below approximately 0.4 maintains 
equivalence for strength for tensile failures with the ETL, regardless of the other parameters.

\section{Recommendations}

67. Near-future revisions of the engineer manual on Strength Design of Reinforced Concrete Hydraulic Structures should mention that the availability of Grade 40 reinforcement is decreasing sharply in this country.

68. Based on the section evaluated in this study, the ACI 318 design criterion with ETL load factors should be considered for structures with Grade 40 (if the use of Grade 40 reinforcement is to be retained) reinforcement in order to improve the economy of some designs above the balance point, yet matching the designs produced by the ETL criterion in some cases (below the balance point). This will utilize design criteria most familiar to engineers. For structures designed with Grade 60 reinforcement, the design criterion for Grade 40 reinforcement should be modified to conform to the ACI 350 durability coefficients. The ACI 350 recommendations were published after the initial development of the Corps' strength design criterion and should now be considered.

69. If use of the analysis \design parameters discussed in this report is adopted, the computer programs CASTR (CORPS X0067) and CGSI (CORPS X0061) will become valid for hydraulic structures. These programs should then be revised for convenient use on both hydraulic structures and structures not subject to hydraulic action. 
ACI Committee 350. 1990 (Jun). "Environmental Engineering Concrete Structures," ACI 350-89, Detroit, MI.

ACI Committee 318. 1989 (Nov). "Building Code Requirements for Reinforced Concrete and Commentary," ACI 318-89, Detroit, MI.

ACI Committee 439. 1989 (Jan-Feb). "Steel Reinforcement-Physical Properties and US Availability," American Concrete Institute Materials Journal, American Concrete Institute, Detroit, MI.

American Standard Technical Manual 615. 1987. Standard Specification for Deformed and Plain Billet - Steel Bars for Concrete Reinforcement, American Society of Testing and Materials, Philadelphia, PA.

Everard, Noel J. 1969. "Ultimate Strength Design - Serviceability Investigation, a Unified Method for Reinforced Concrete Bridge Design," Paper SP 23-22, American Concrete Institute, Detroit, MI.

Gergely, P. and Lutz, L. A. 1968. "Maximum Crack Width in Reinforced Concrete Flexural Members," Cause. Mechanism, and Control of Cracking in Concrete, Special Publication SP-20, American Concrete Institute, Detroit, MI.

Hamby, C. C. and Price, W. A. 1984. "User's Guide for Concrete Strength Investigation and Design (CSTR)," Instruction Report K-84-9, US Army Engineer Waterways Experiment Station, Vicksburg, MS.

Headquarters, Department of the Army. 1988 (Mar). "Strength Design Criteria for Reinforced Concrete Hydraulic Structures," Engineer Technical Letter ETL 1110-2-312, Washington, DC.

- 1981 (Sep). "Strength Design Criteria for Reinforced Concrete Hydraulic Structures, " Engineer Technical Letter ETL 1110-2-265, Washington, DC.

1963 (Nov). "Working Stresses for Structural Design," Engineer Manual 1110-1-2101, Washington, DC.

Liu, Tony C. 1980 (Jul). "Strength Design of Reinforced Concrete Hydraulic Structures, Report 2, Design Aids for Use in the Design and Analysis of Reinforced Concrete Hydraulic Structures," Technical Report SL-80-4, US Army Engineer Waterways Experiment Station, Vicksburg, MS. 


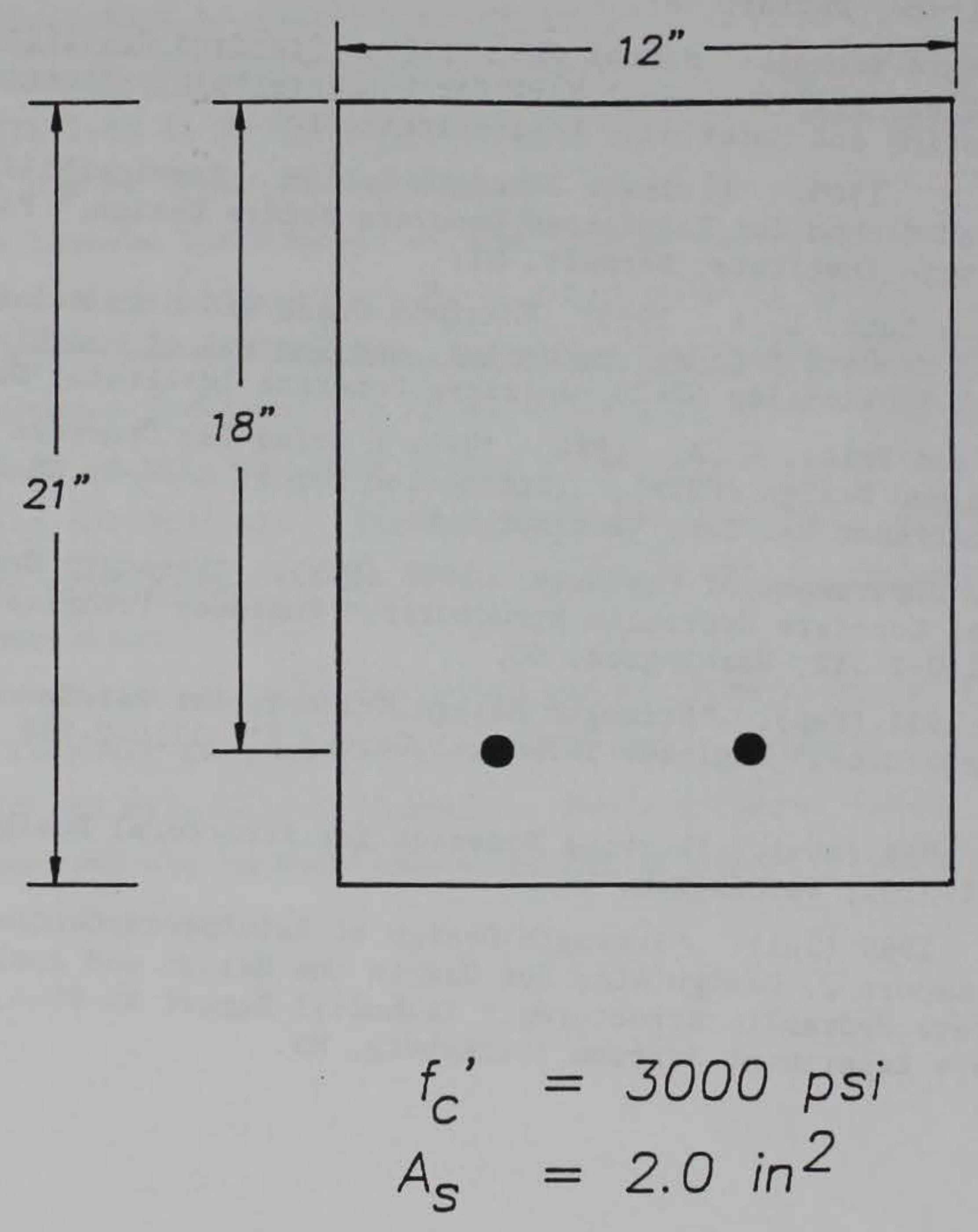

Figure 1. Singly-reinforced beam 


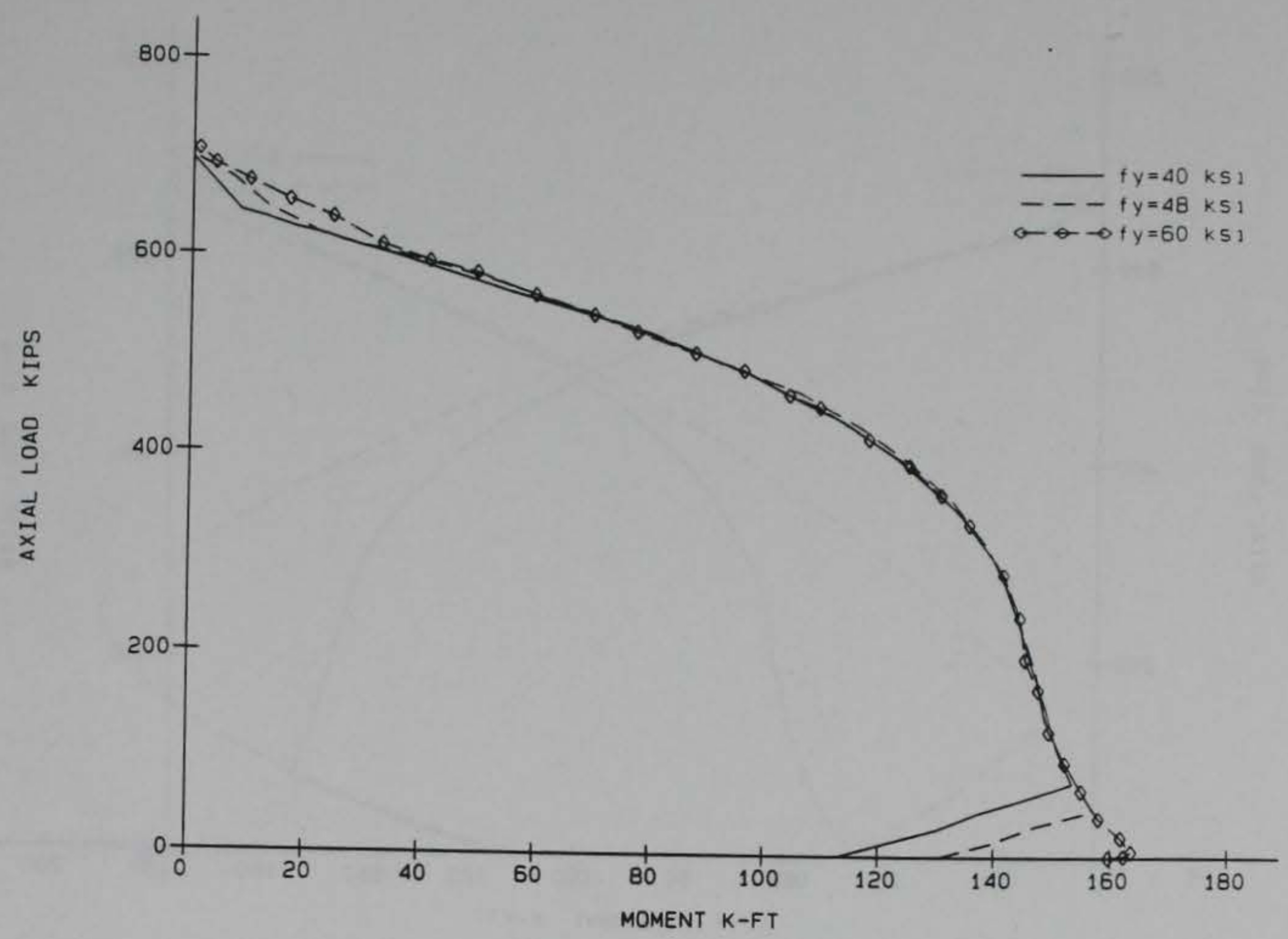

Figure 2. Effect of $f_{y}$ for ETL

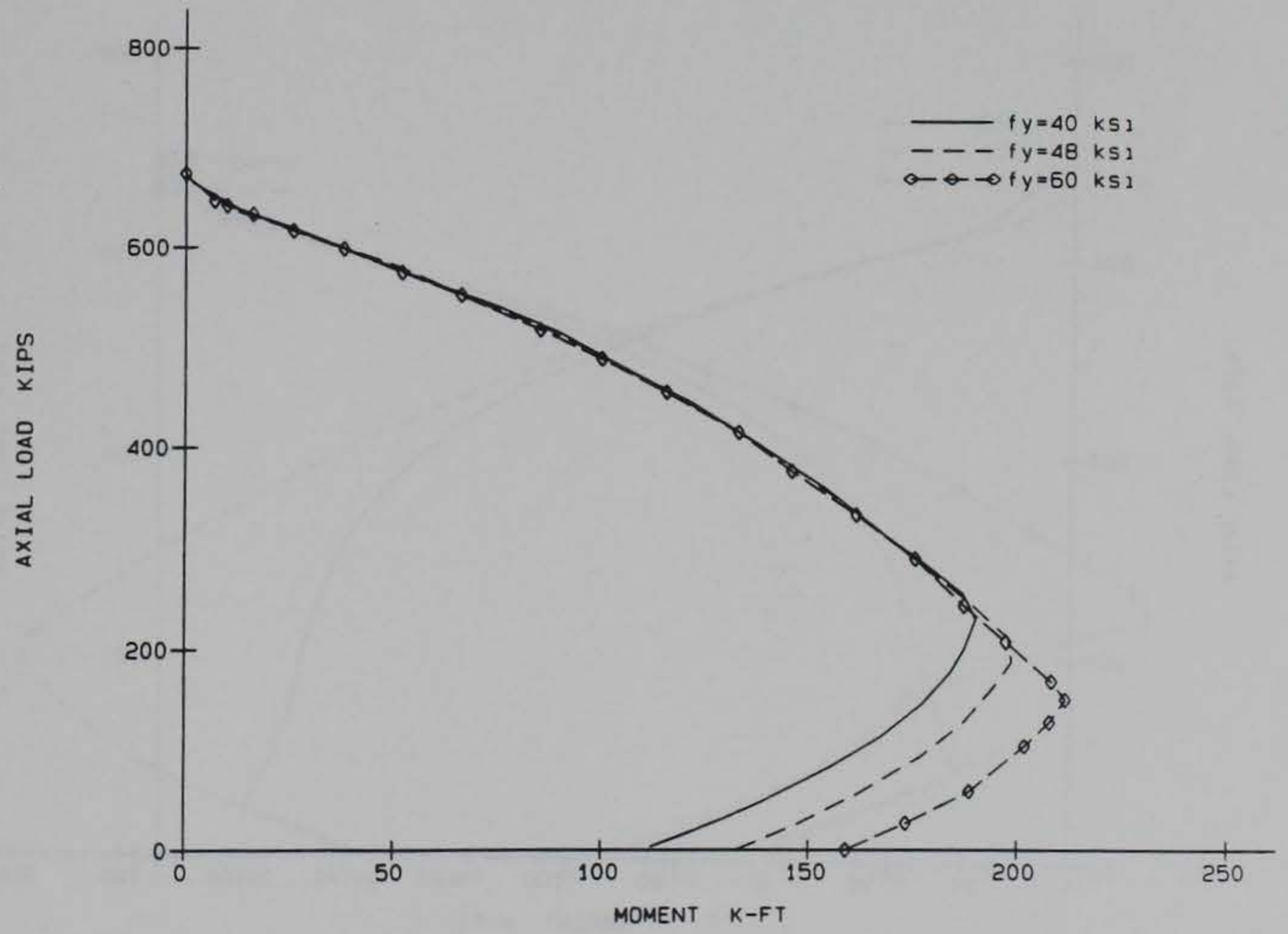

Figure 3. Effect of $f_{y}$ for ACI 


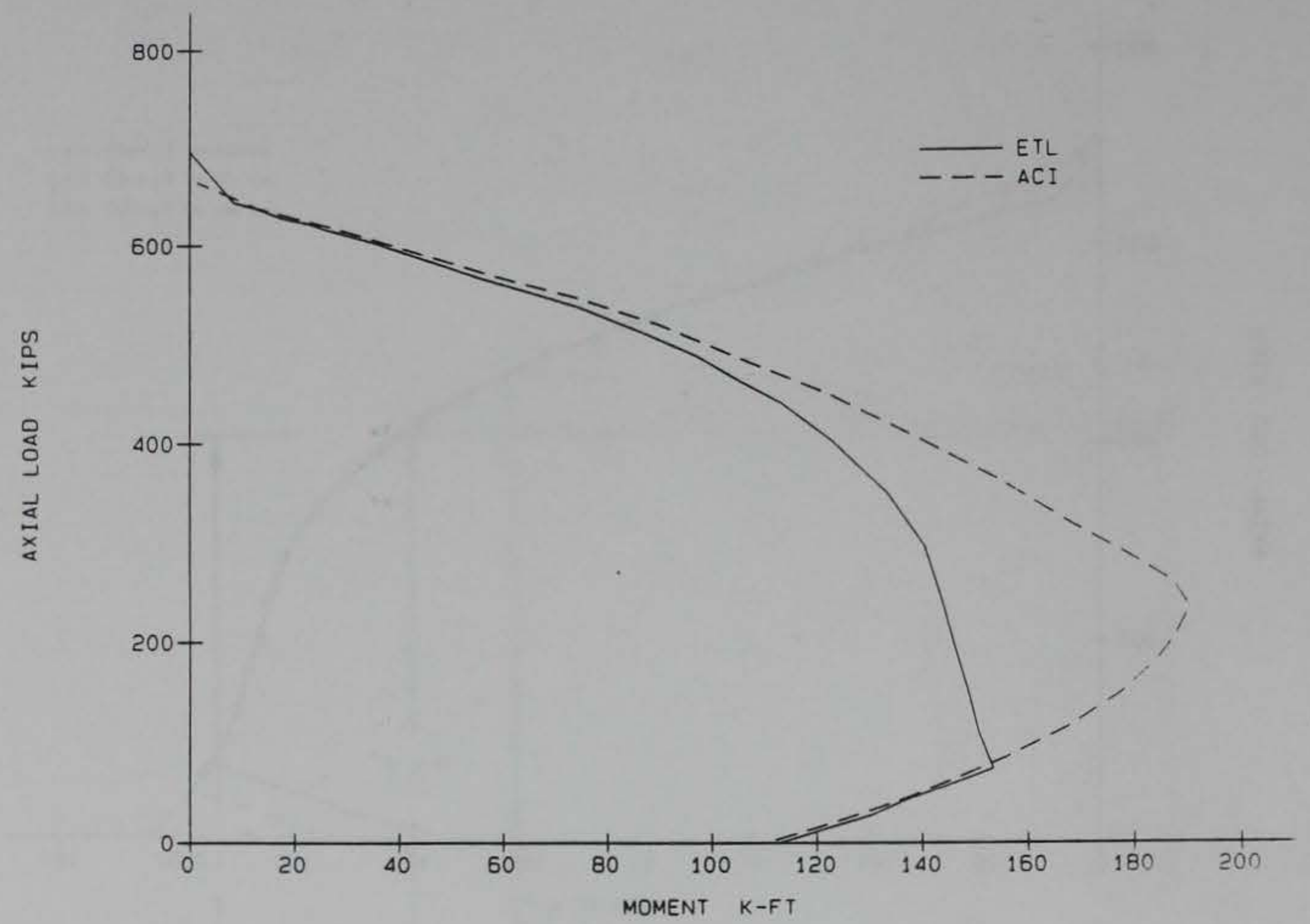

Figure 4. ETL versus ACI for $f_{y}=40 \mathrm{ksi}$

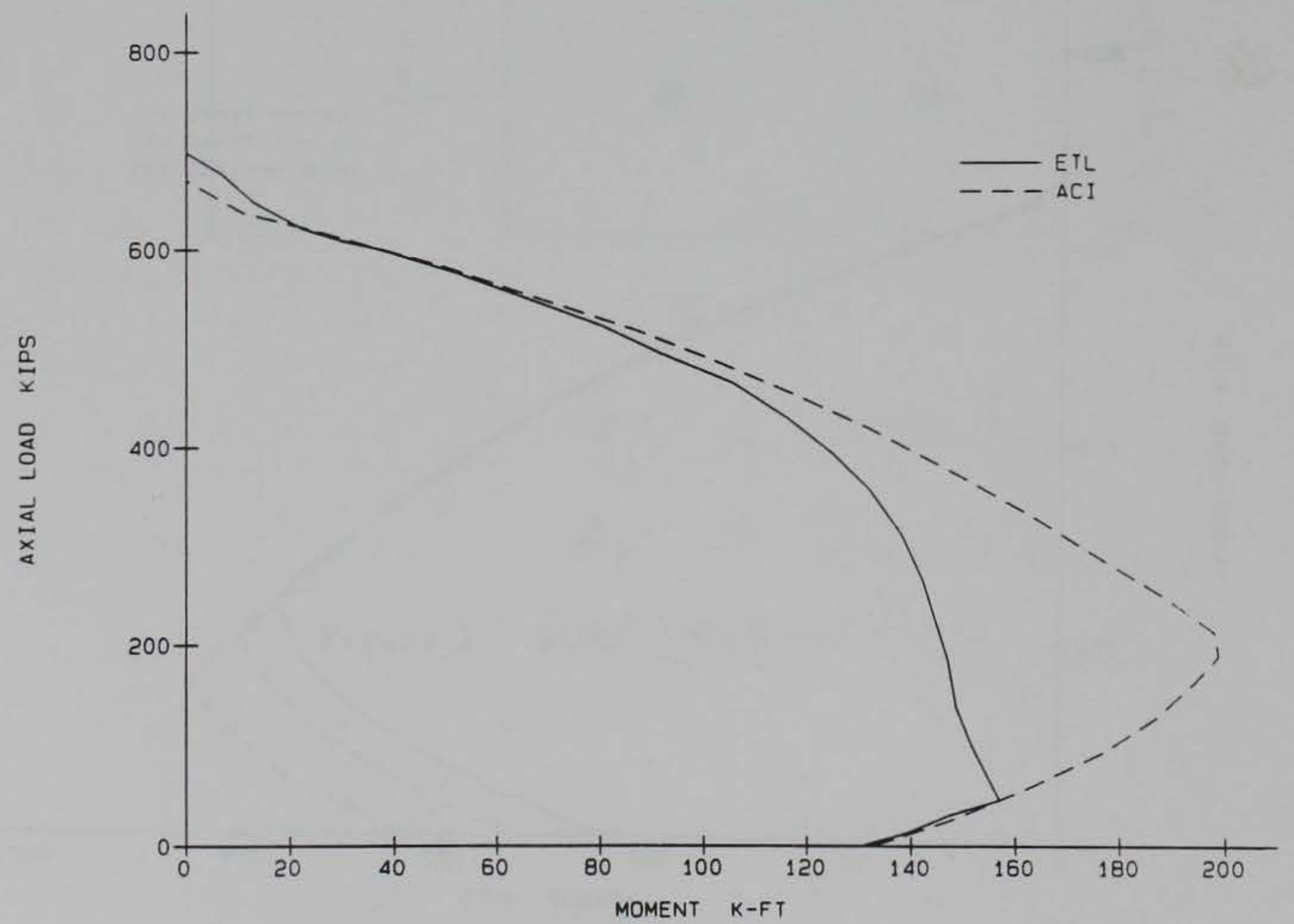

Figure 5. ETL versus ACI for $f_{y}=48 \mathrm{ksi}$ 


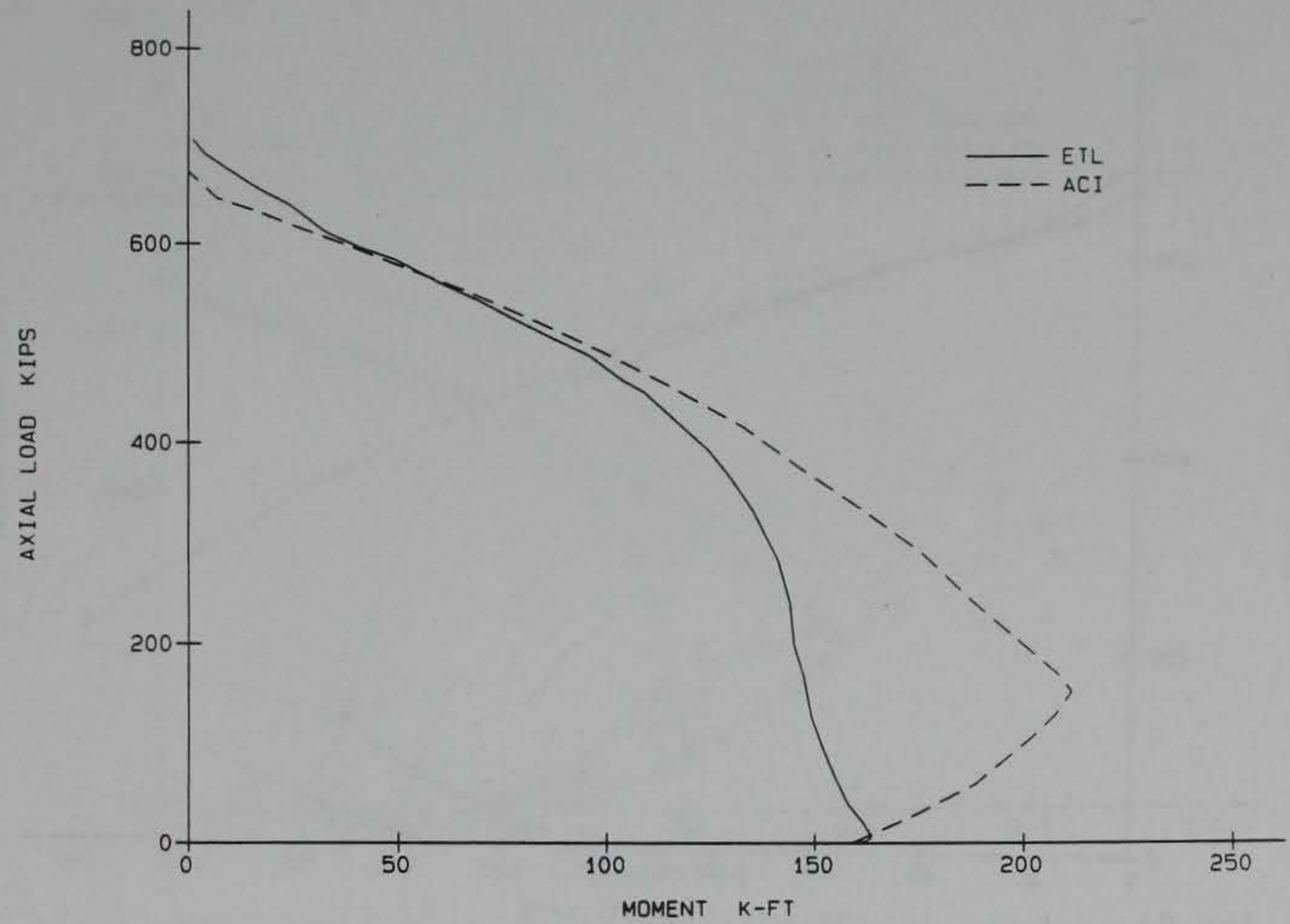

Figure 6. ETL versus ACI for $f_{y}=60 \mathrm{ksi}$

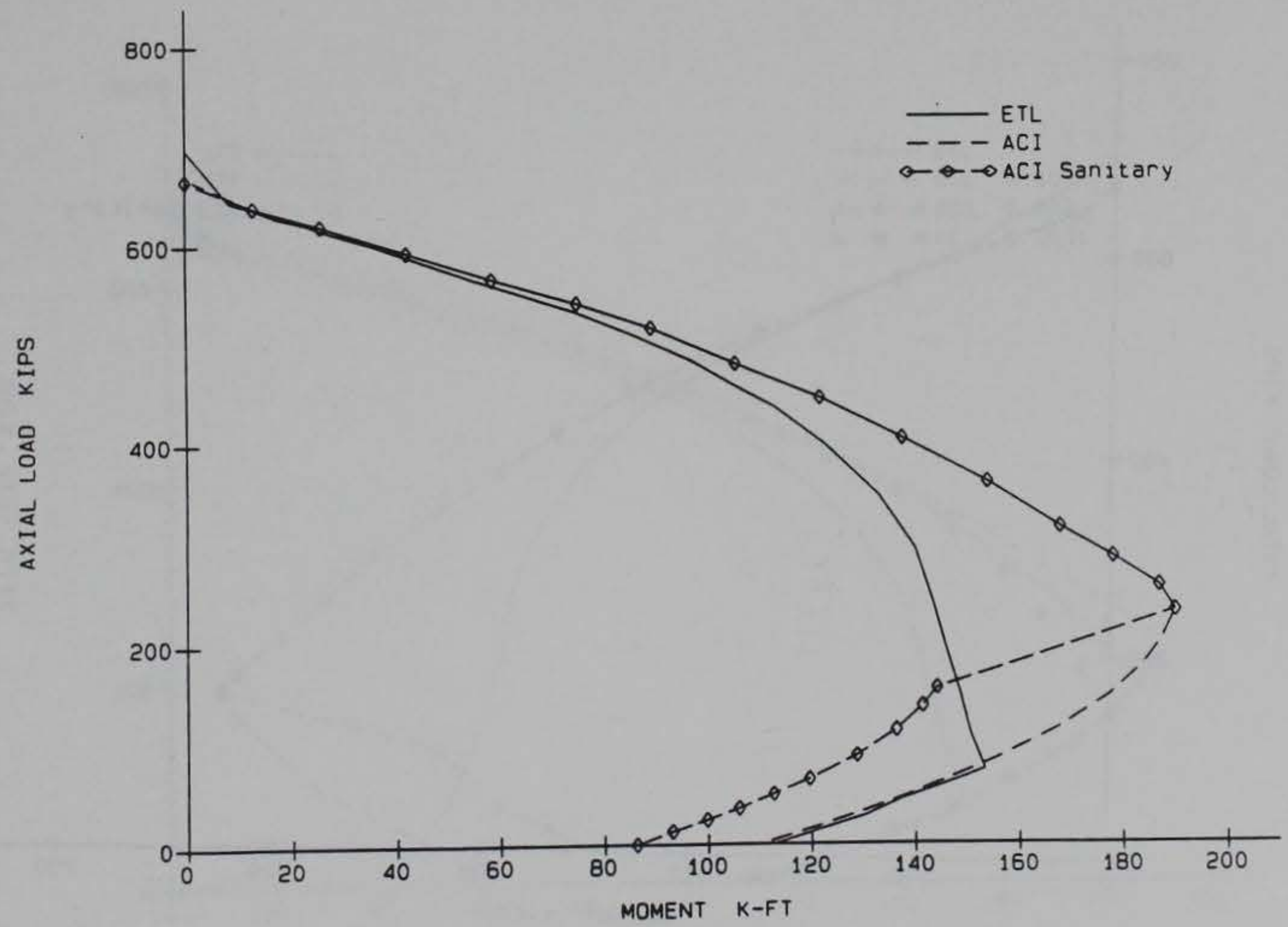

Figure 7. ETL, ACI, and ACI Sanitary for $f_{y}=40 \mathrm{ksi}$ 


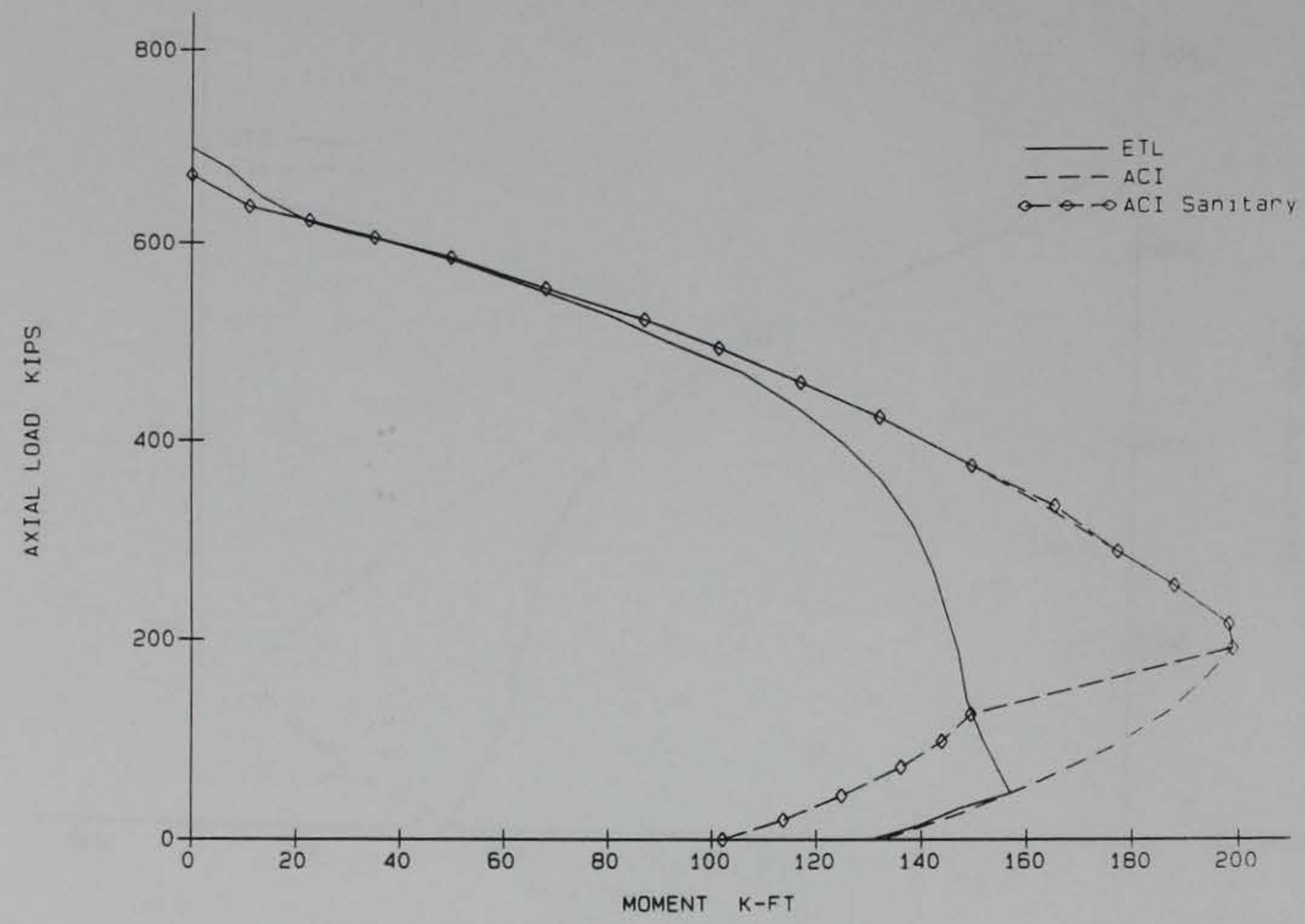

Figure 8. ETL, ACI, and ACI Sanitary for $f_{y}=48 \mathrm{ksi}$

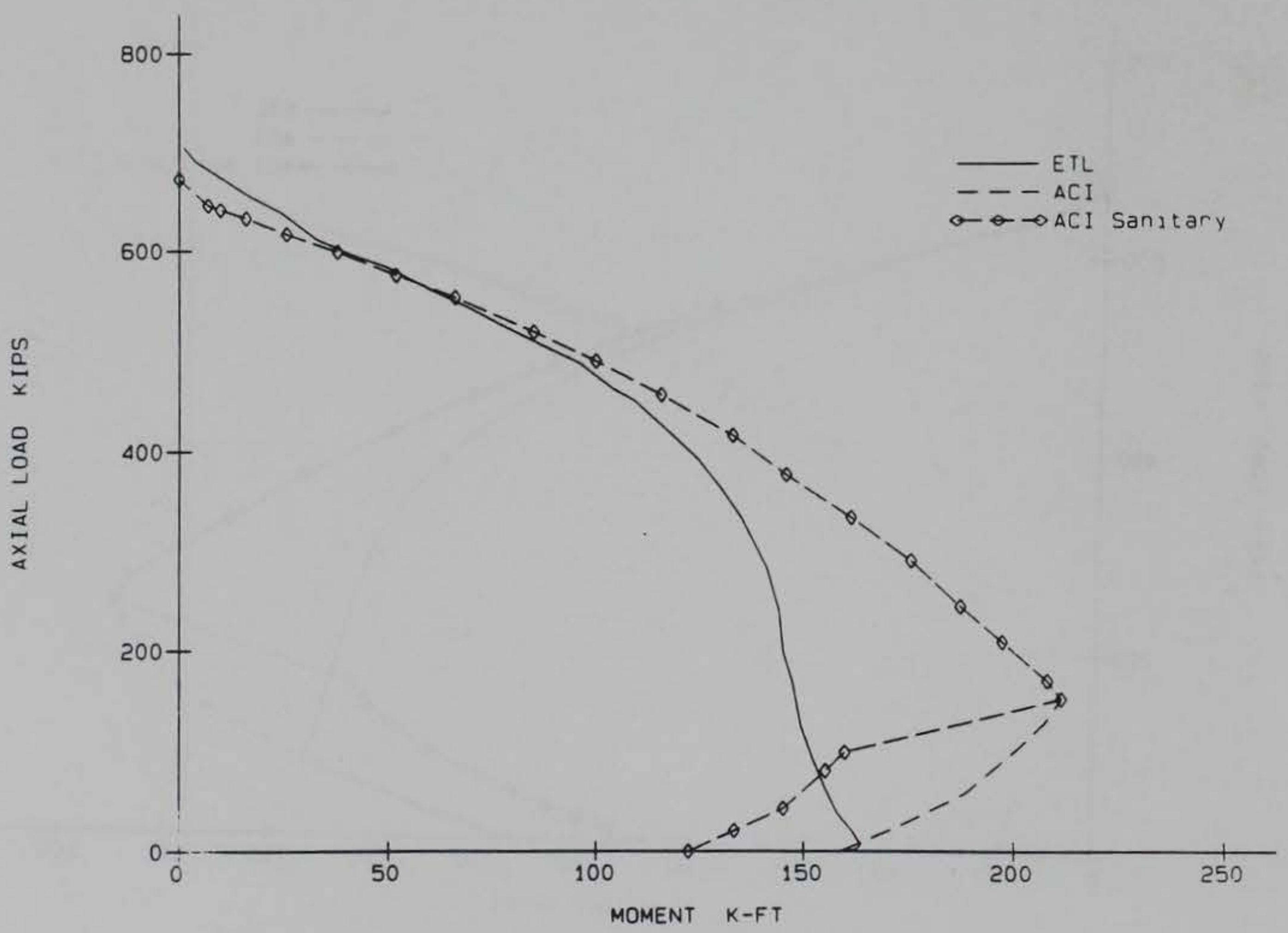

Figure 9. ETL, ACI, and ACI Sanitary for $f_{y}=60 \mathrm{ksi}$ 


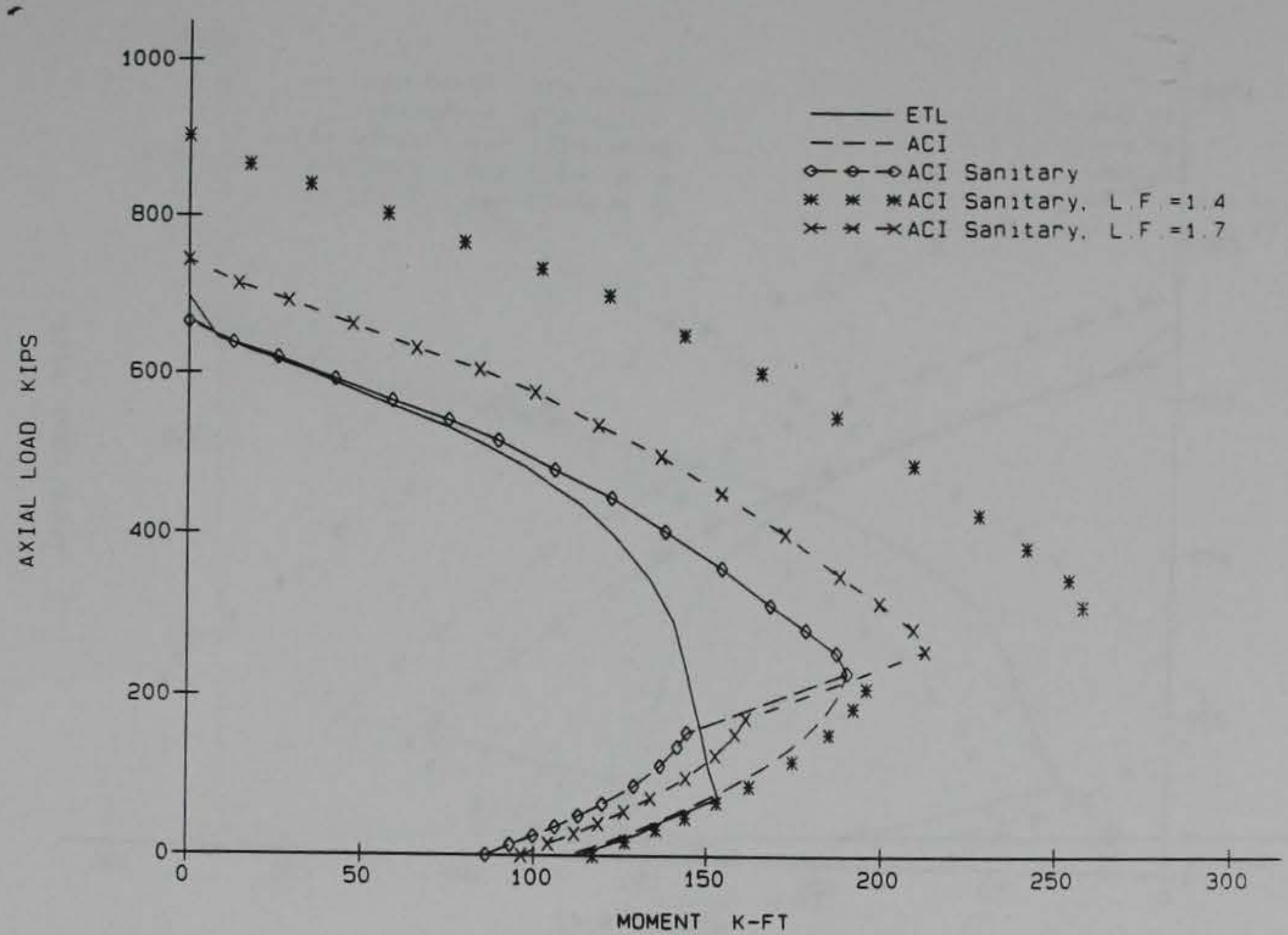

Figure 10. ETL, ACI, and ACI Sanitary for $f_{y}$ equal to $40 \mathrm{ksi}$, L.F. $=1.4$ or 1.7

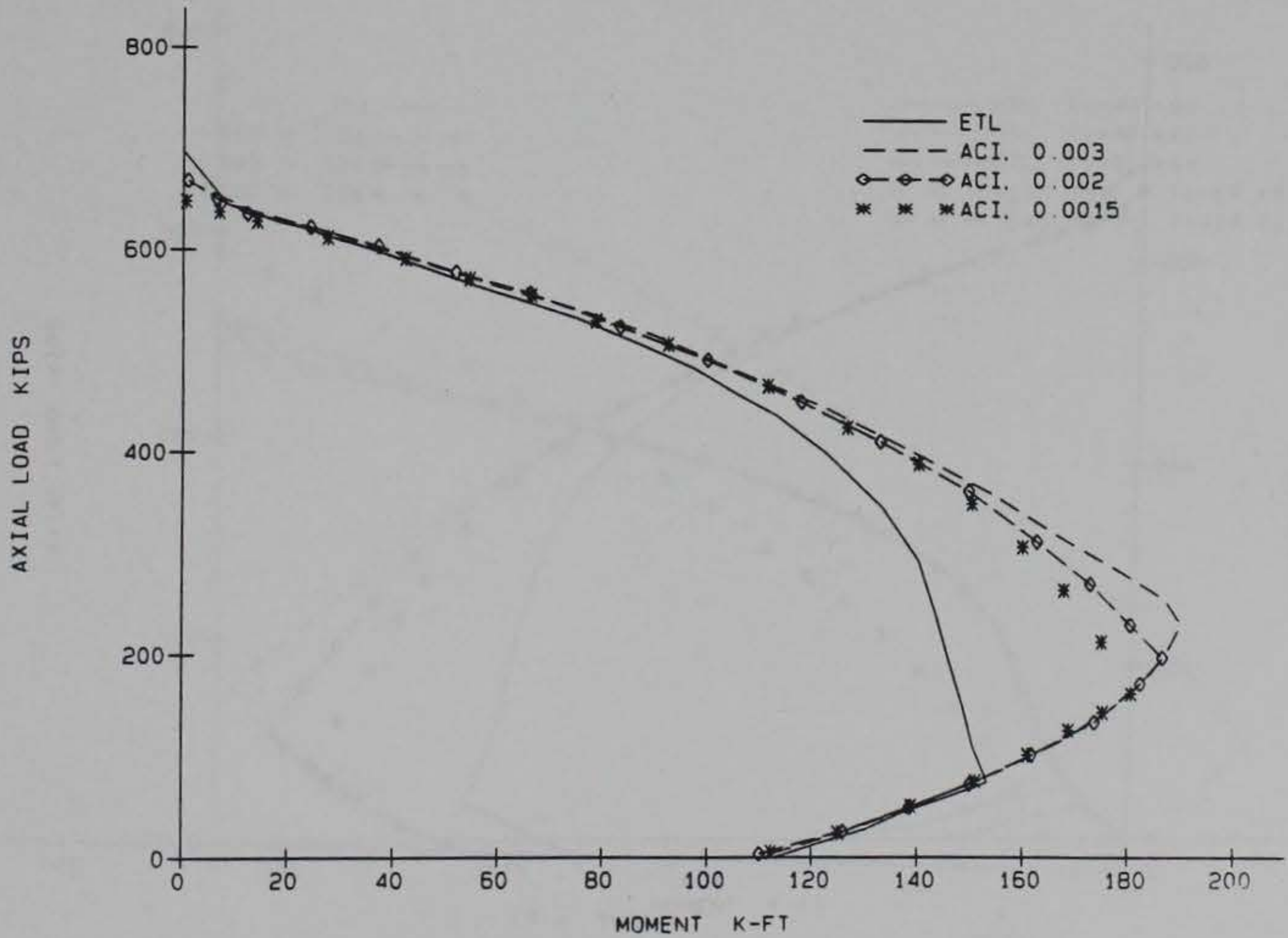

Figure 11. Maximum concrete strain, Grade 40 


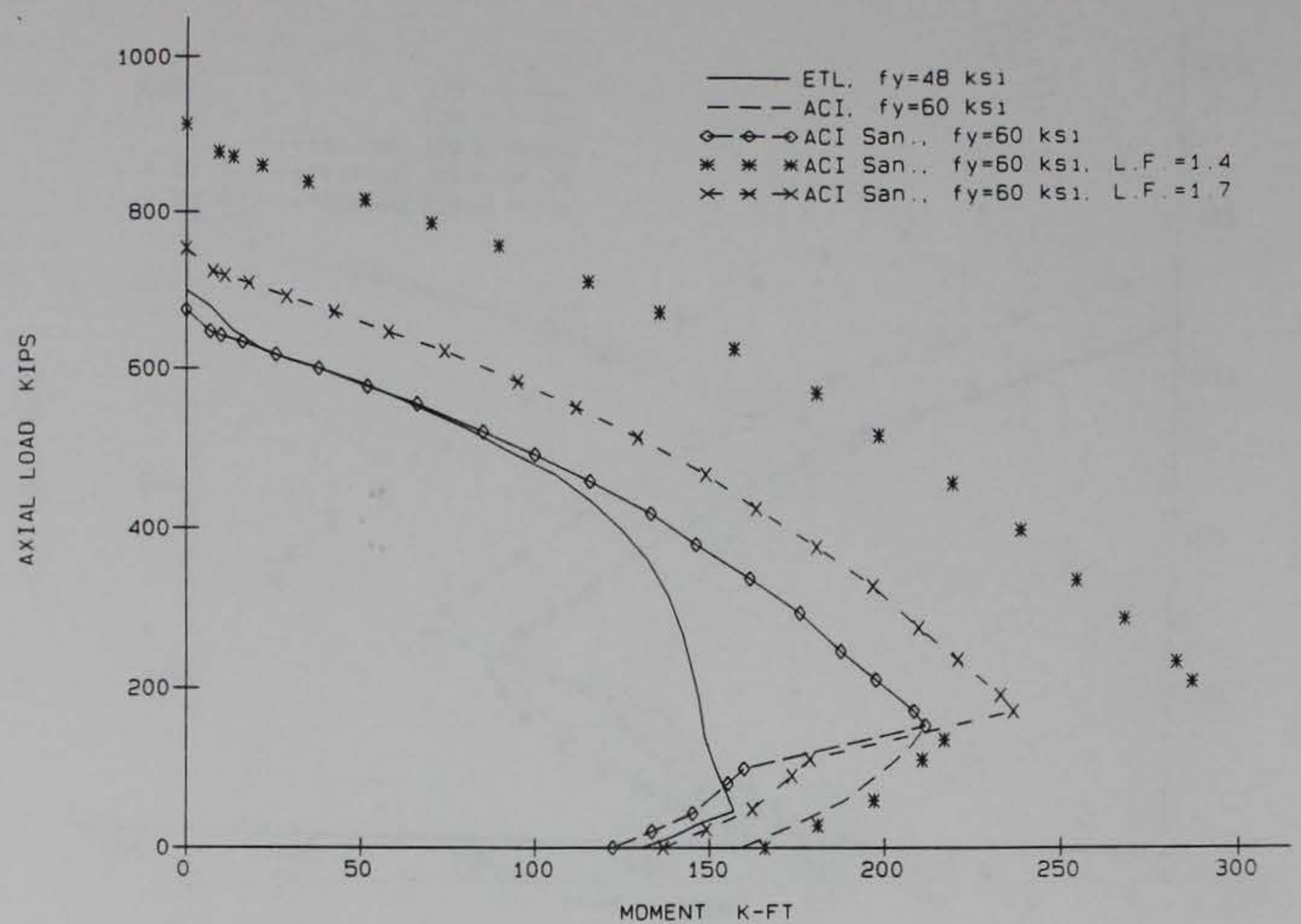

Figure 12. ETL, ACI, ACI Sanitary, Grade 60,

L. $F$. $=1.4$ or 1.7

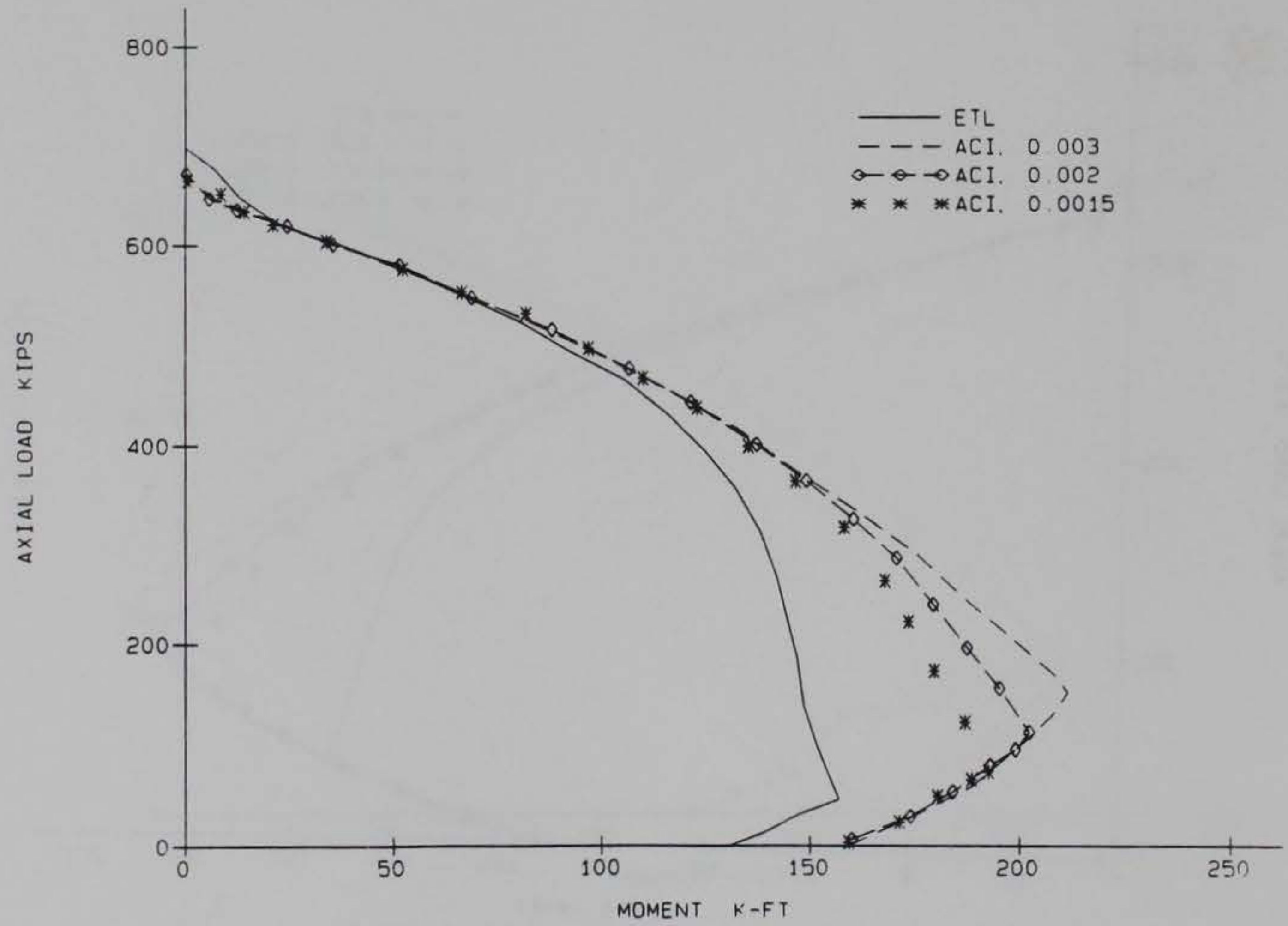

Figure 13. Maximum concrete strain, Grade 60 


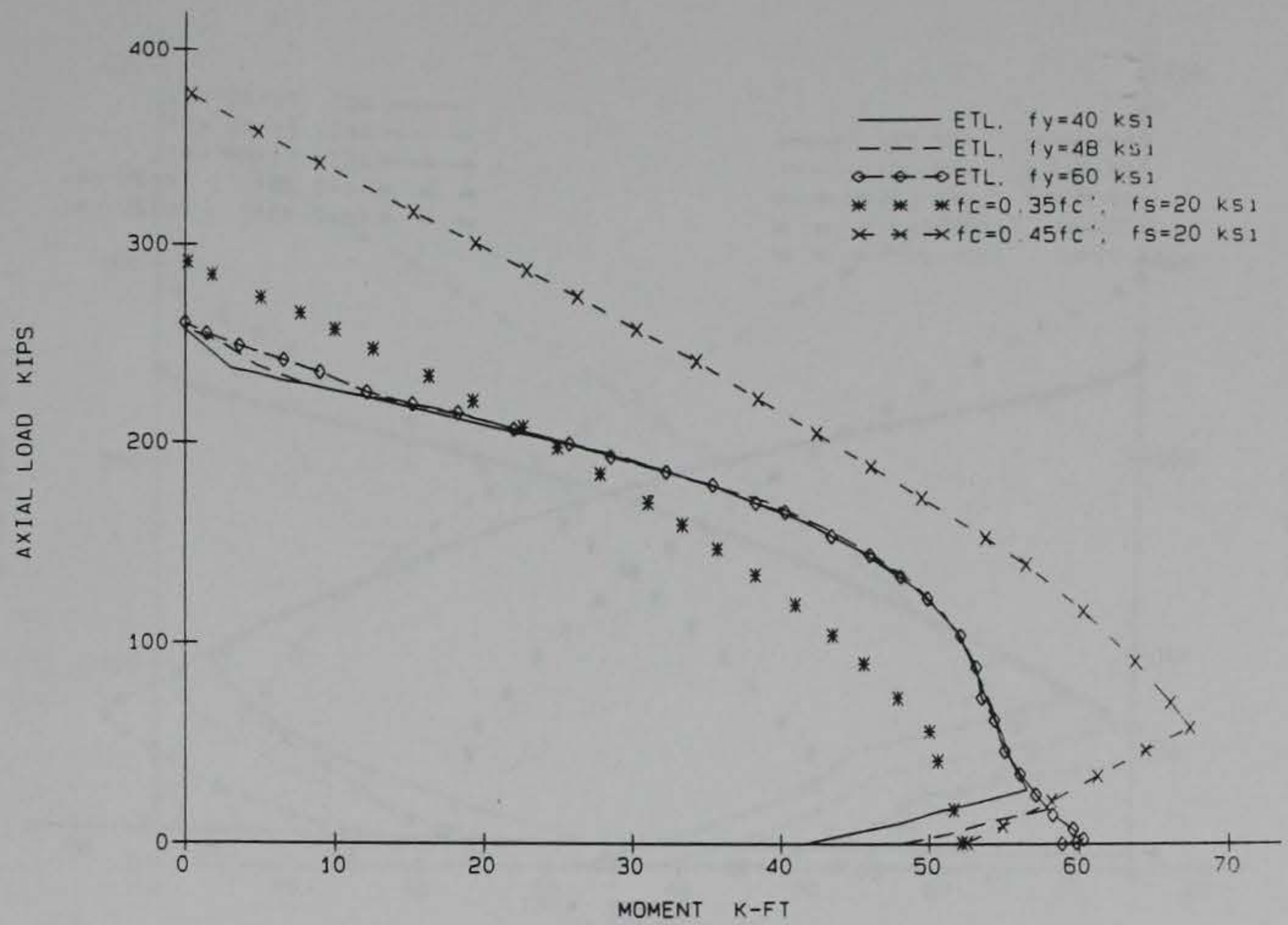

Figure 14. ETL strength versus working stress, phi $=0.7$, $f_{s}=20 \mathrm{ksi}$

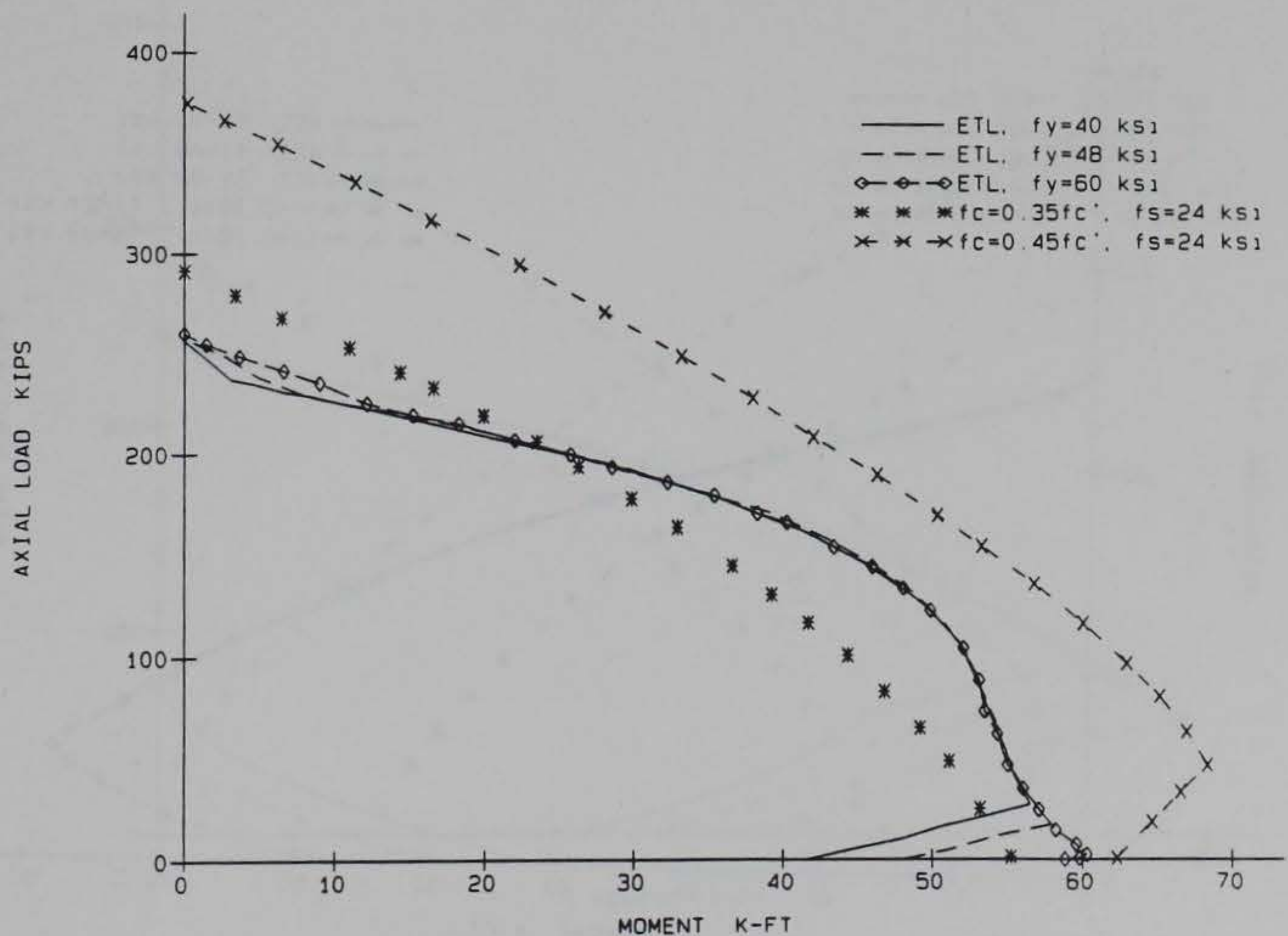

Figure 15. ETL strength versus working stress, phi $=0.7$, $f_{s}=24 \mathrm{ksi}$ 


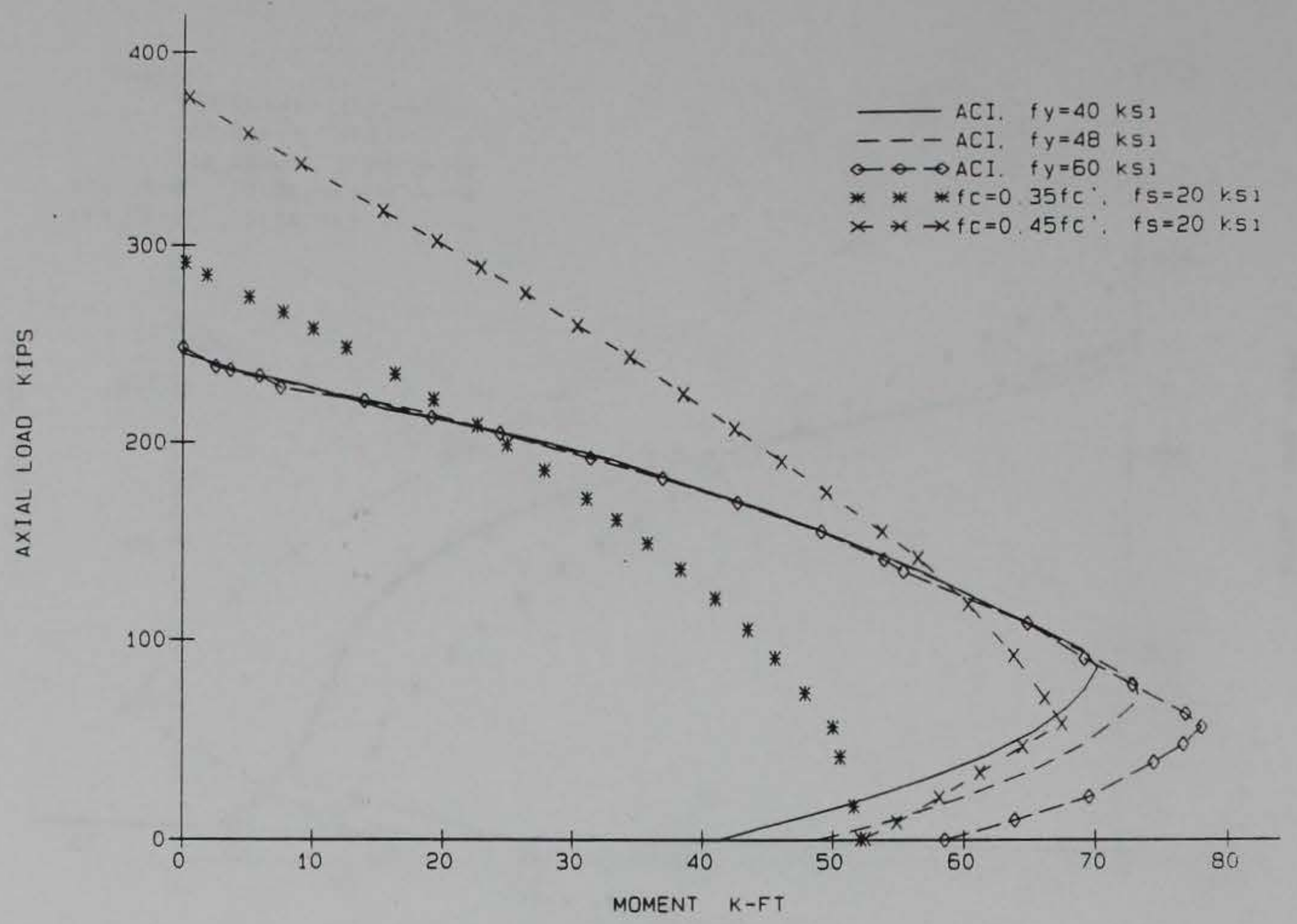

Figure 16. ACI strength versus working stress, phi $=0.7$, $f_{s}=20 \mathrm{ksi}$

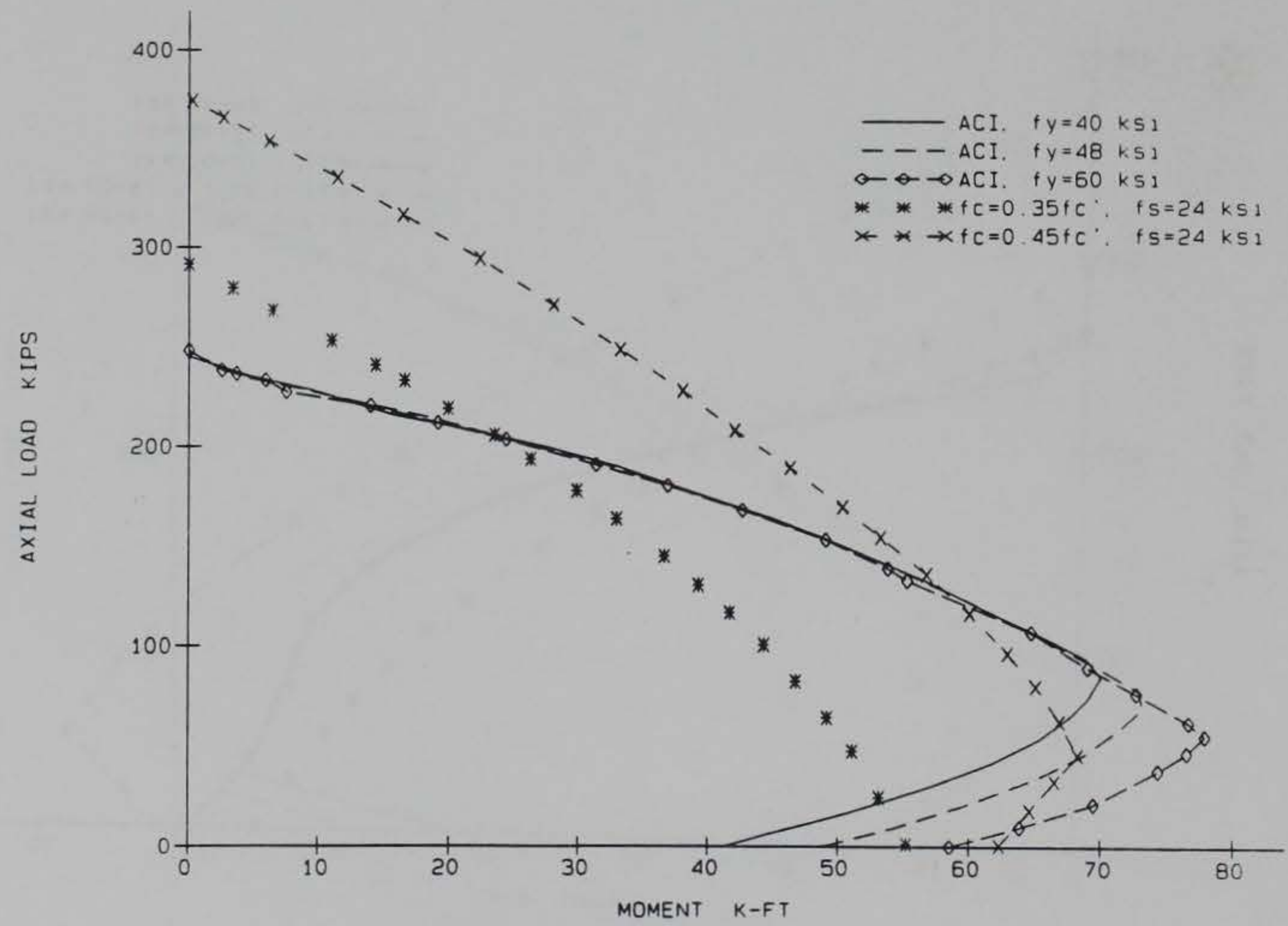

Figure 17. ACI strength versus working stress, phi $=0.7$,

$$
f_{s}=24 \mathrm{ksi}
$$




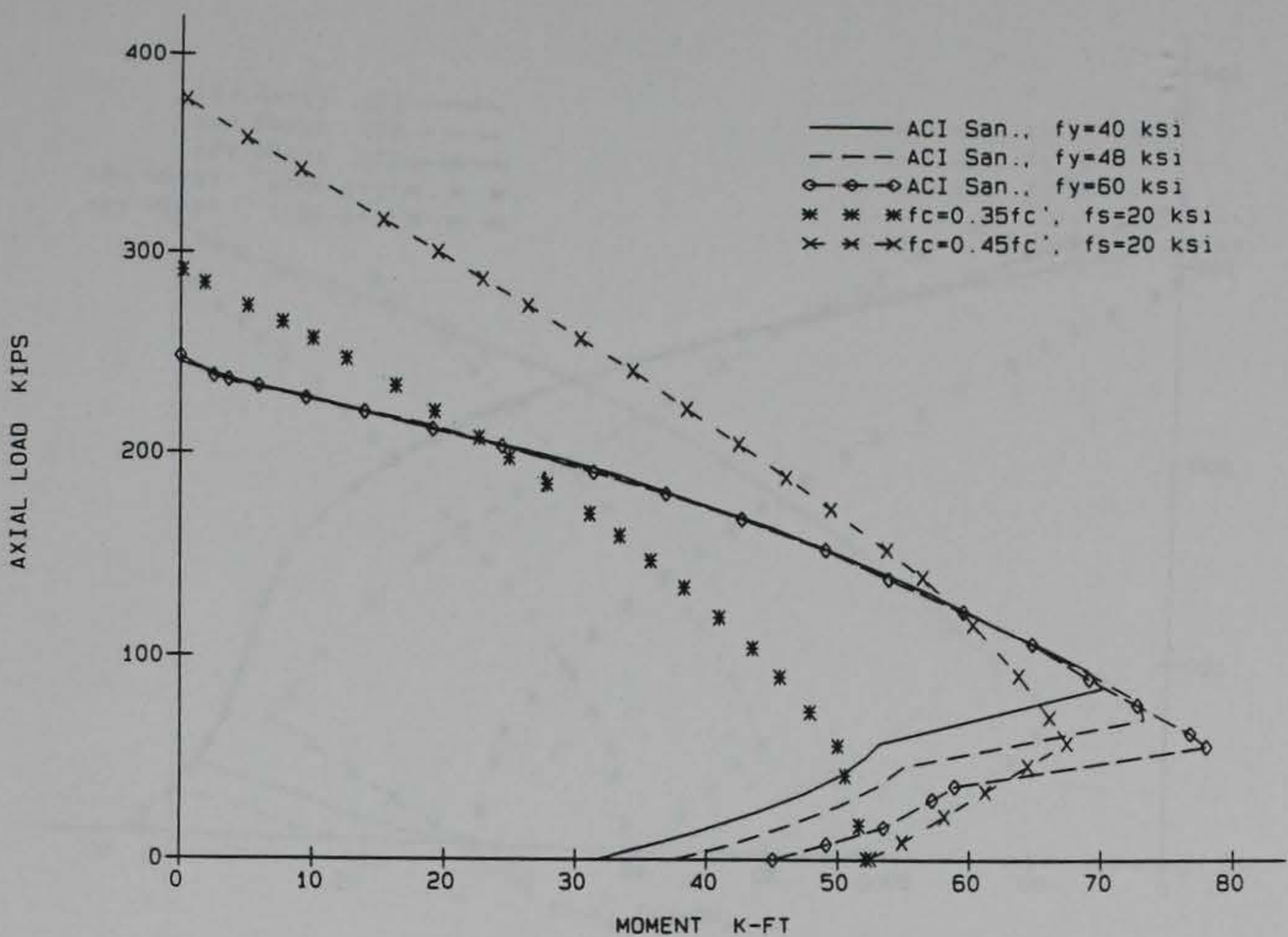

Figure 18. ACI sanitary strength versus working stress, phi $=0.7, f_{s}=20 \mathrm{ksi}$

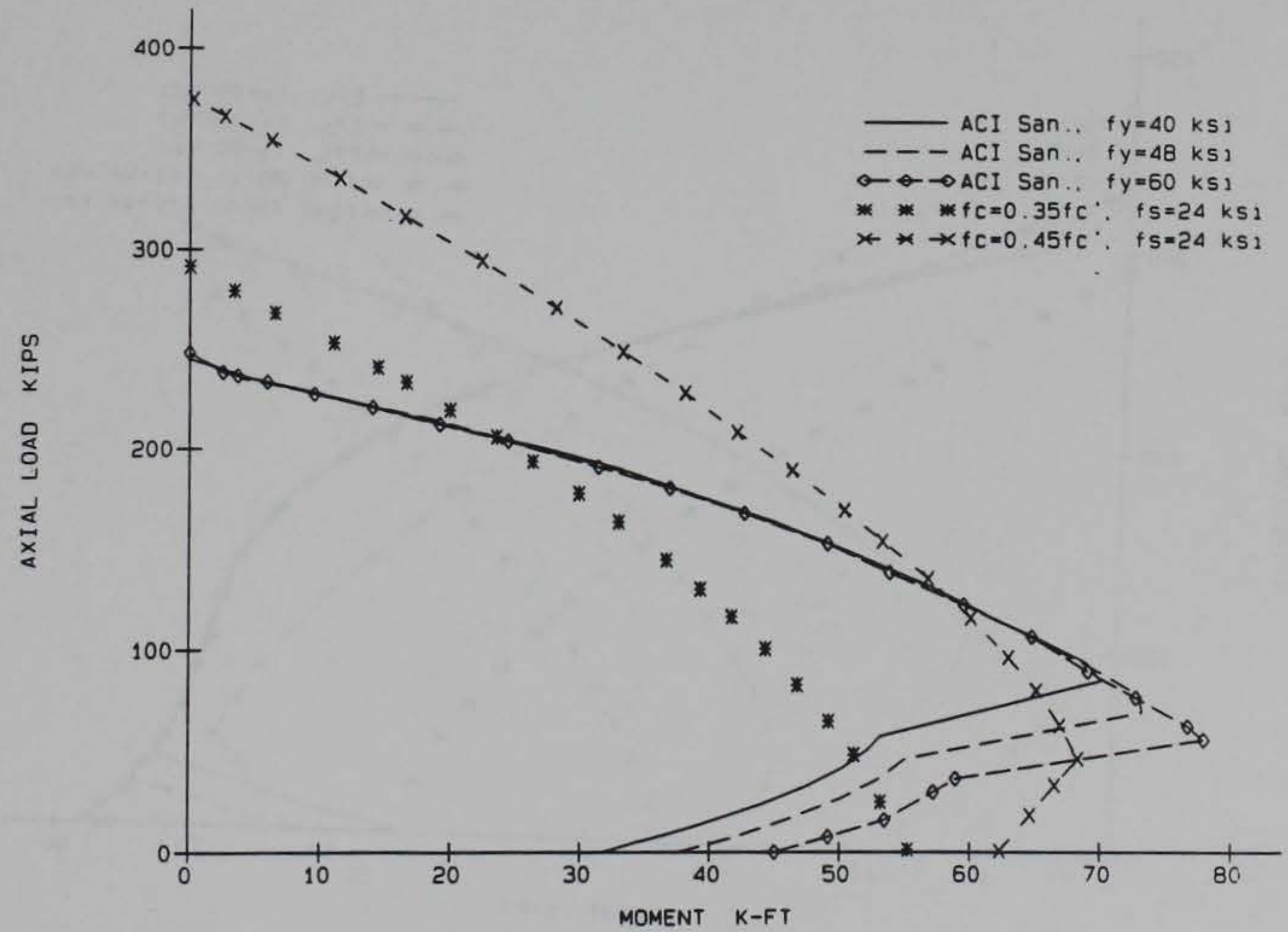

Figure 19. ACI sanitary strength versus working stress, phi $=0.7, f_{s}=24 \mathrm{ksi}$ 


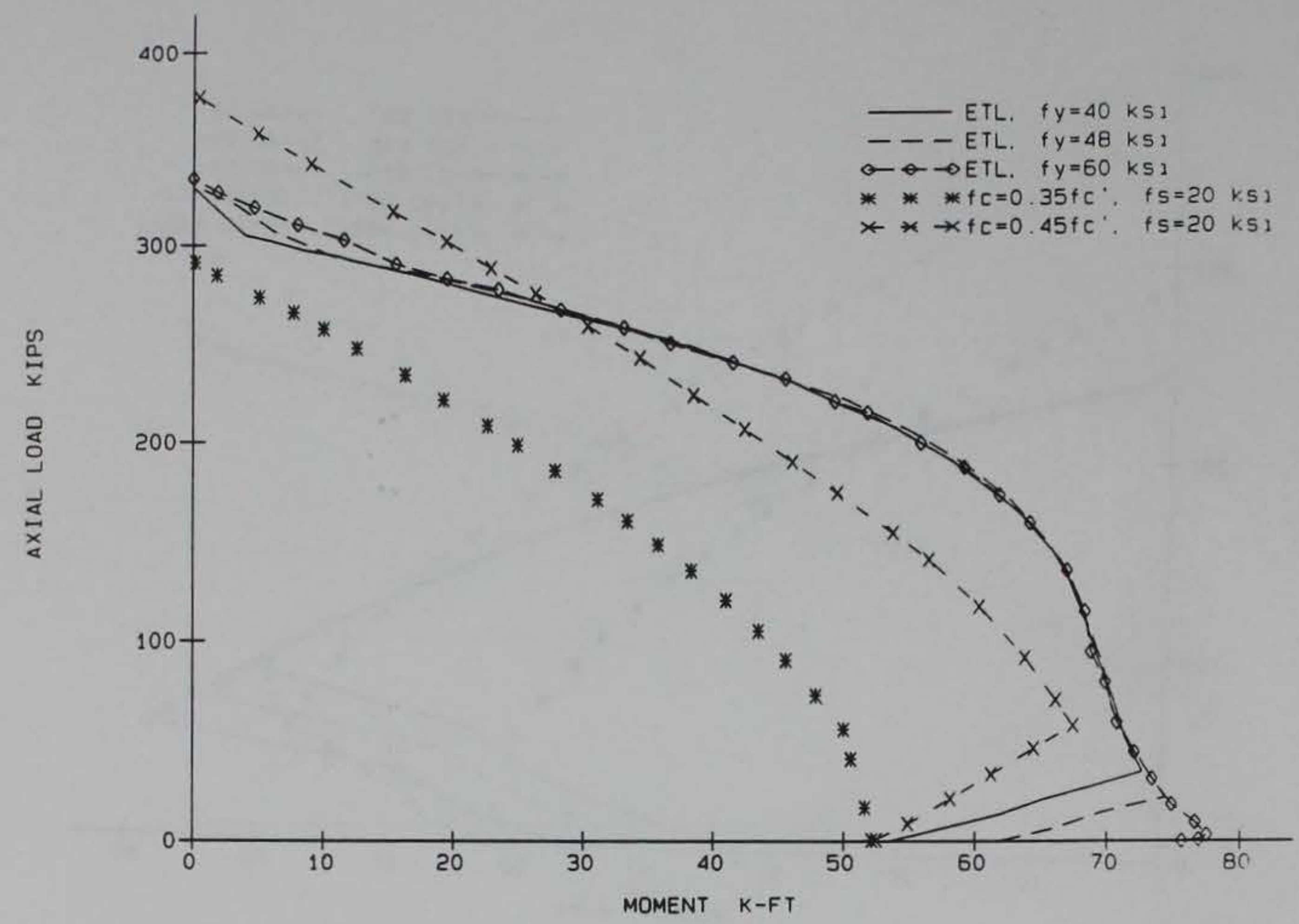

Figure 20. ETL strength versus working stress, phi $=0.9$, $f_{s}=20 \mathrm{ksi}$

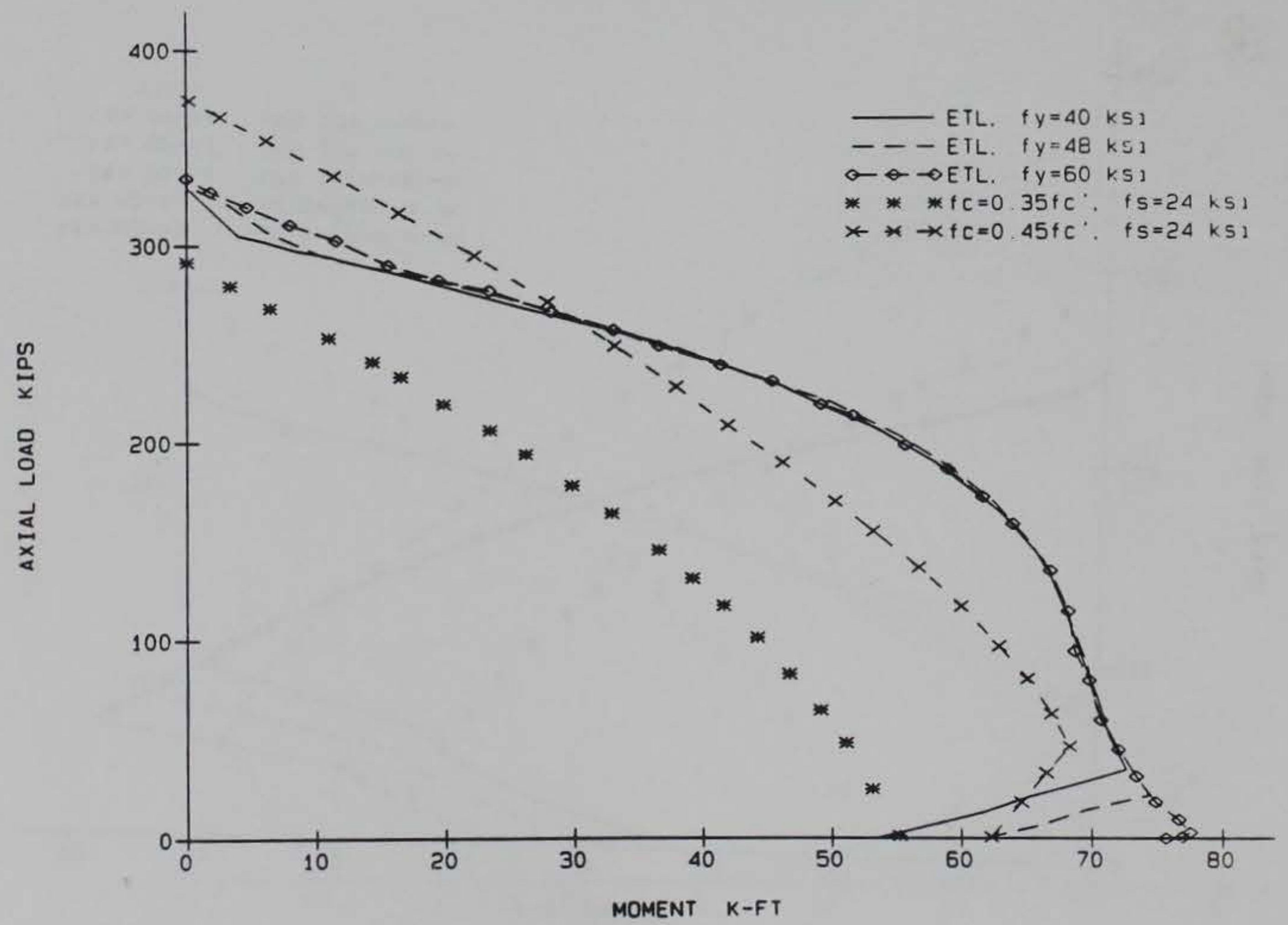

Figure 21. ETL strength versus working stress, phi $=0.9$, $f_{s}=24 \mathrm{ksi}$ 


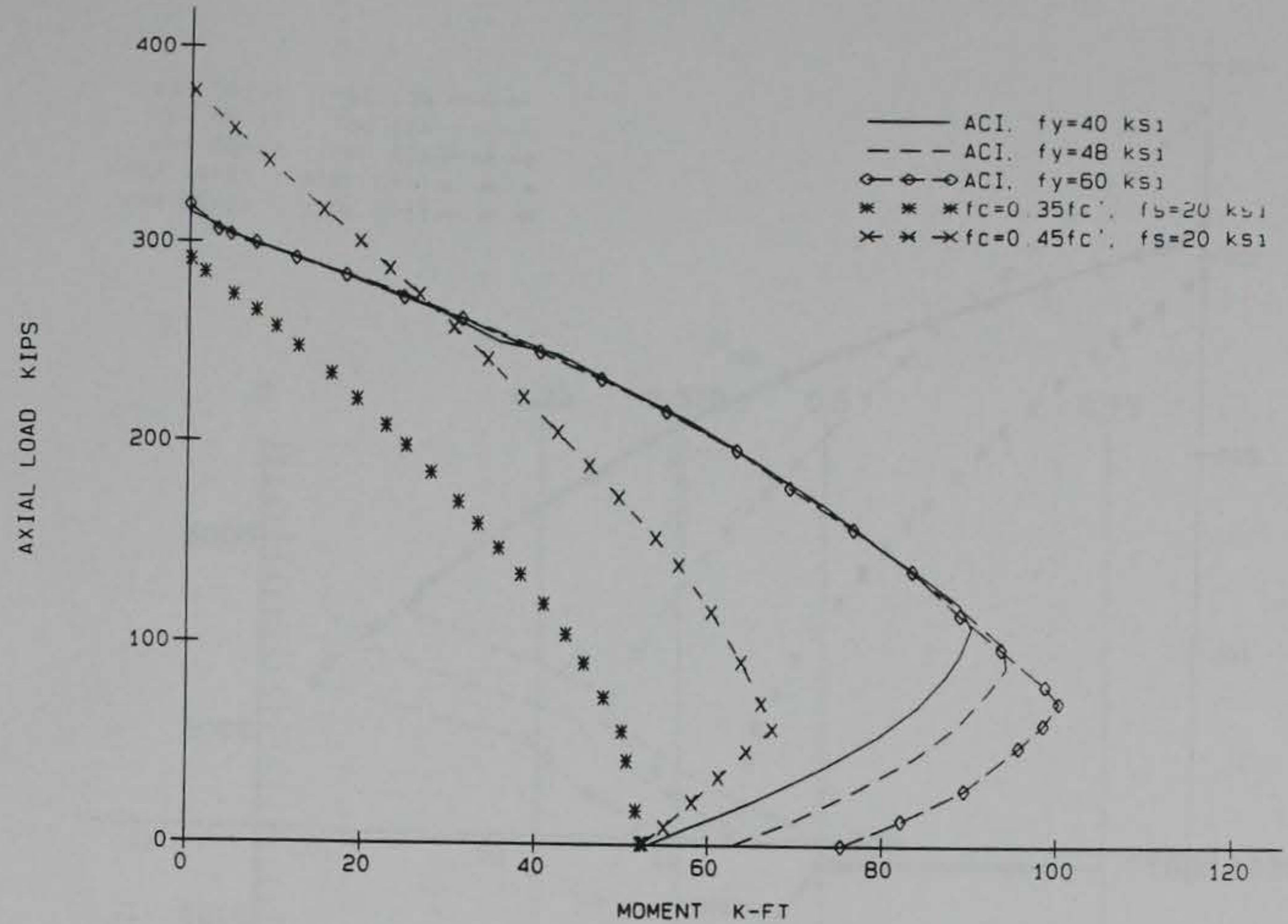

Figure 22. ACI strength versus working stress, phi $=0.9$, $f_{\mathrm{s}}=20 \mathrm{ksi}$

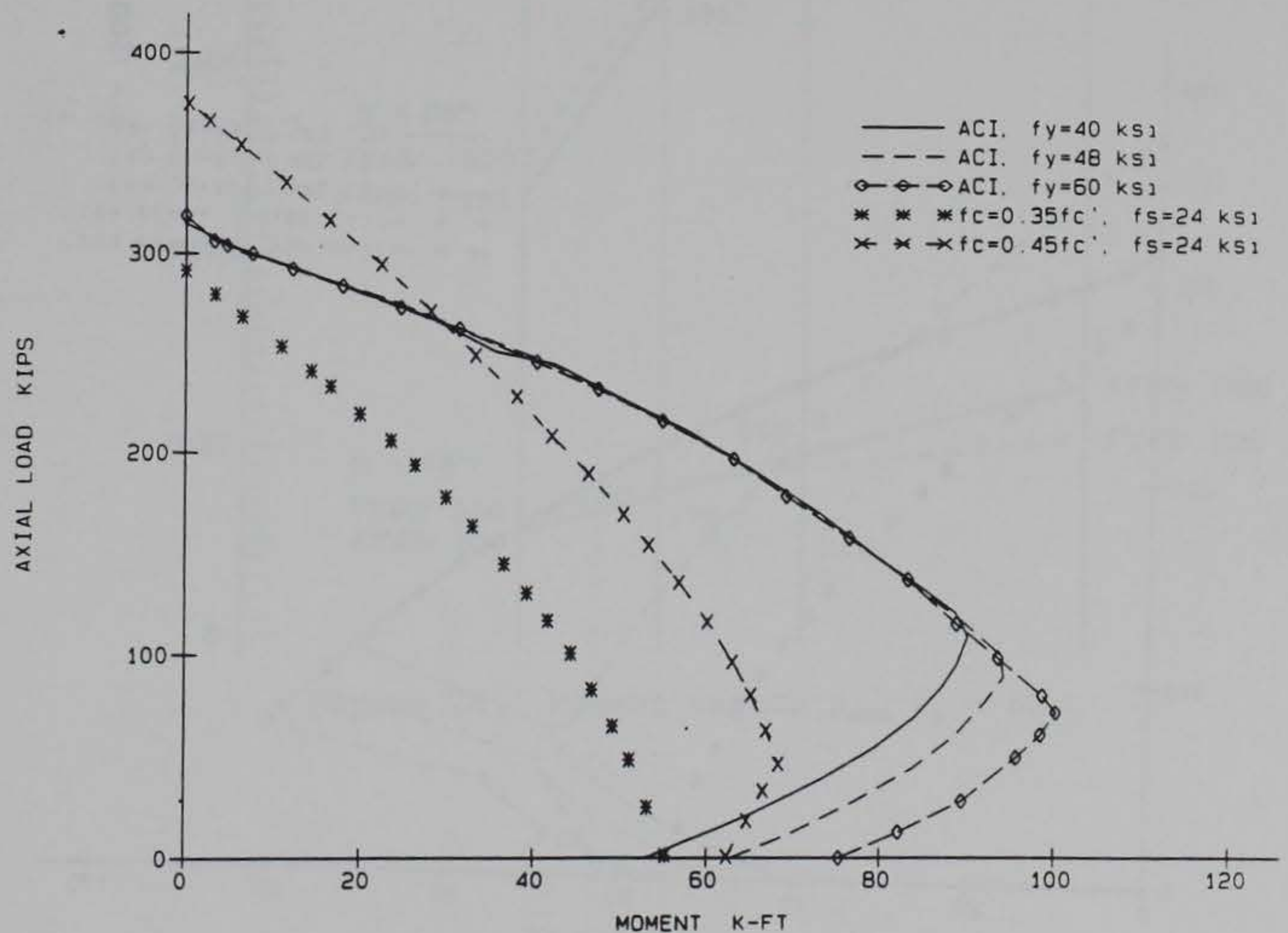

Figure 23. ACI strength versus working stress, phi $=0.9$, $f_{s}=24 \mathrm{ksi}$ 


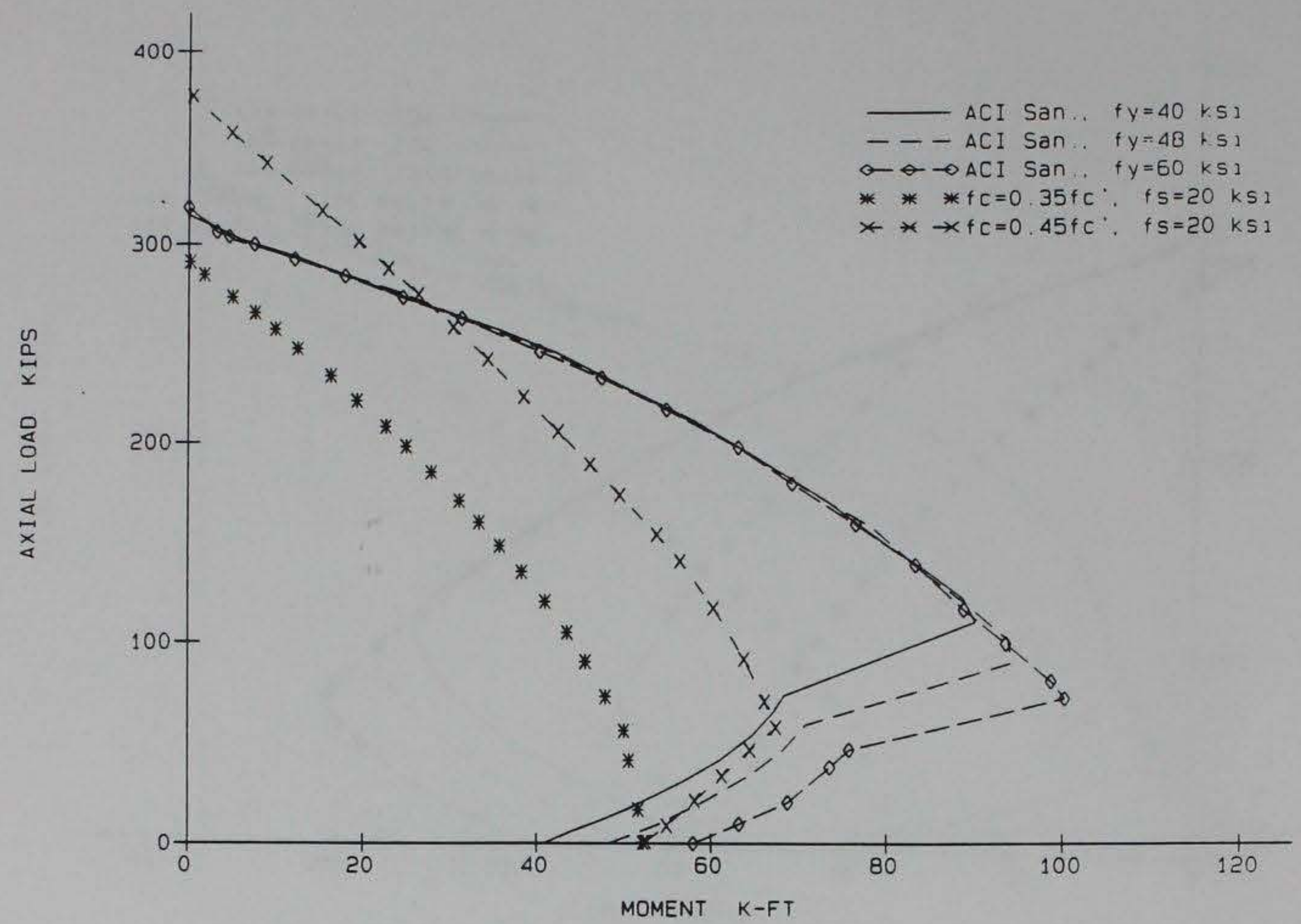

Figure 24. ACI sanitary strength versus working stress, phi $=0.9, f_{s}=20 \mathrm{ksi}$

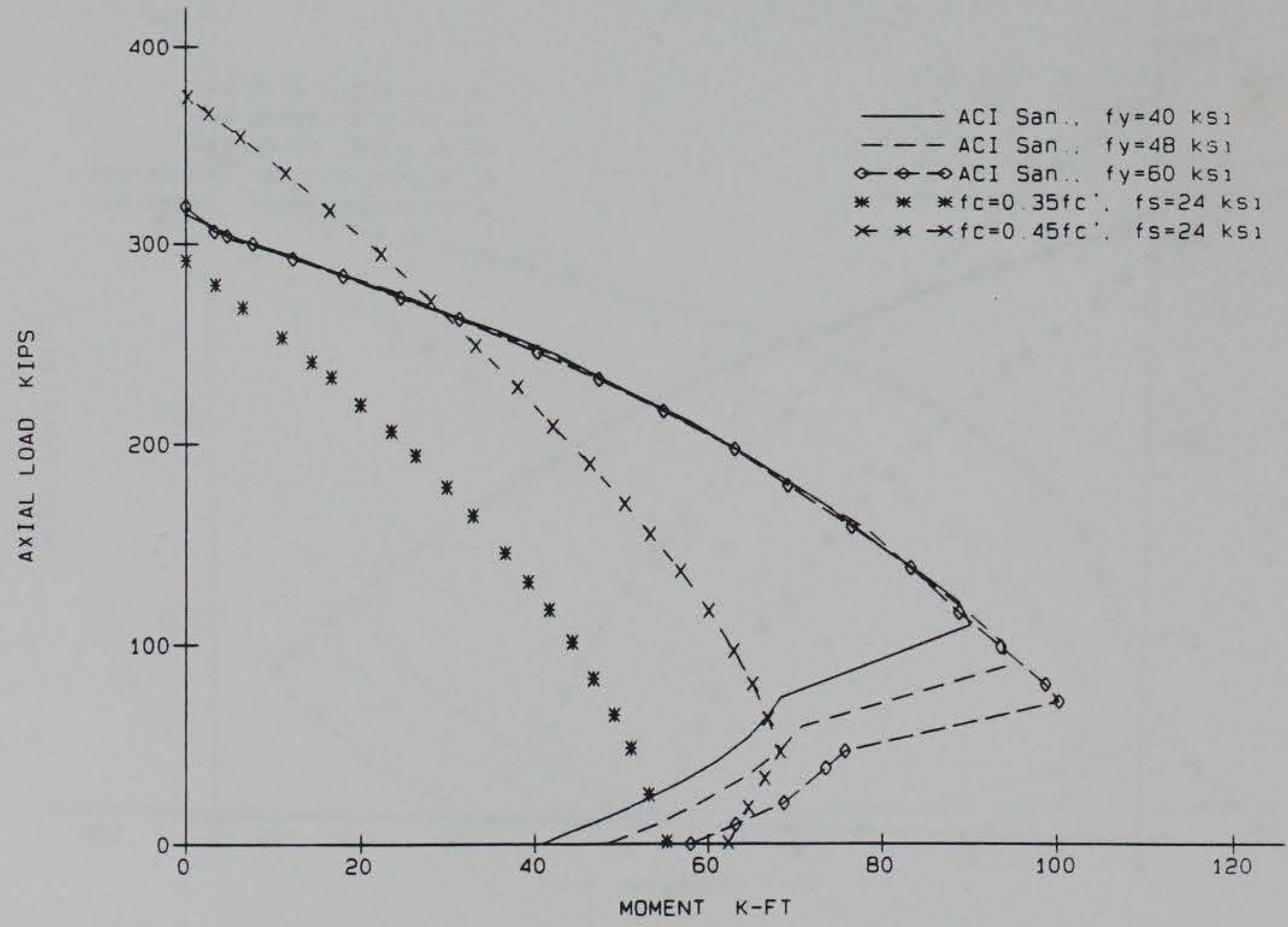

Figure 25. ACI sanitary strength versus working stress, phi $=0.9, f_{s}=24 \mathrm{ksi}$ 


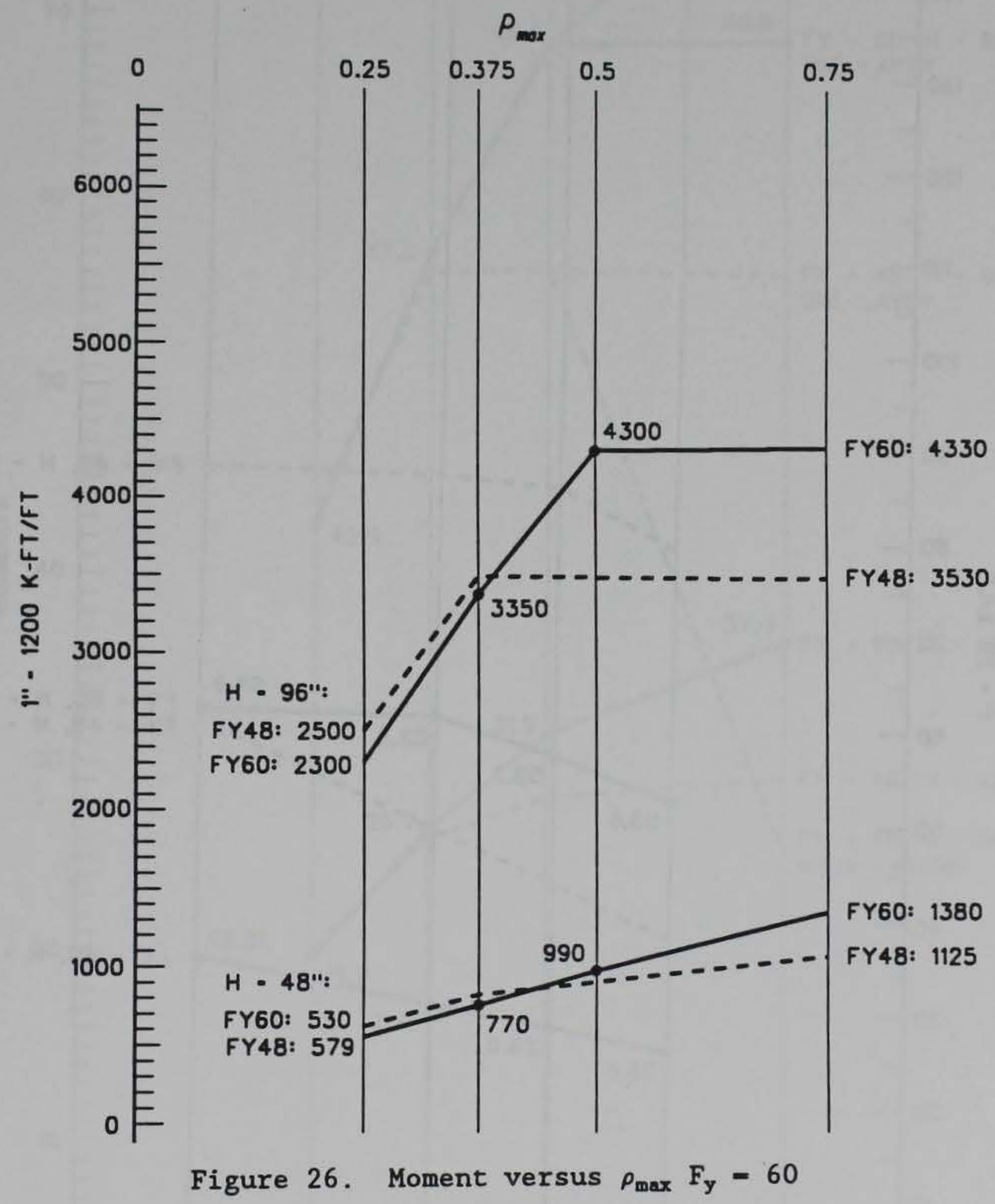



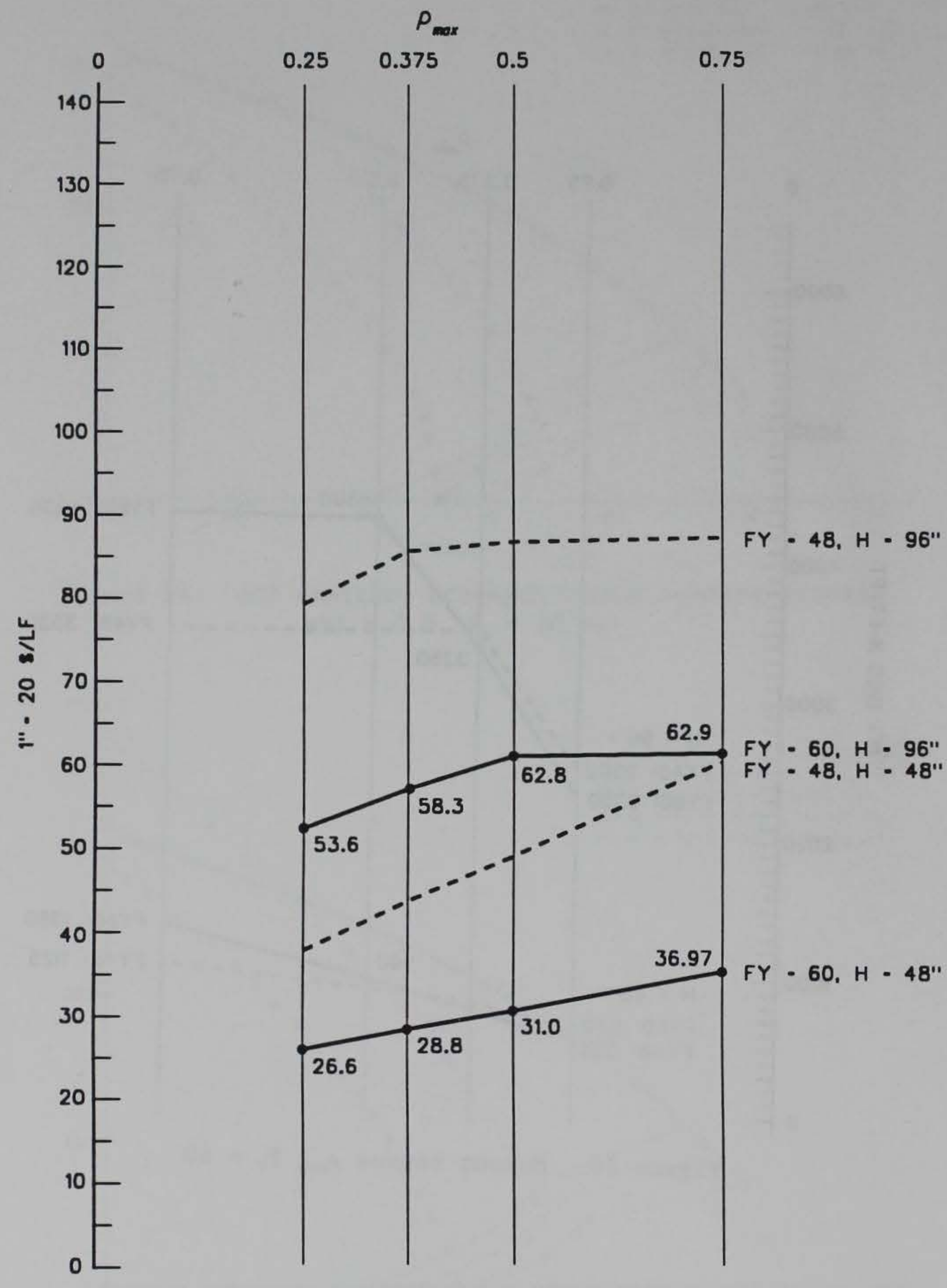

Figure 2- Cost versus $\rho_{\max } F_{y}=60$ 


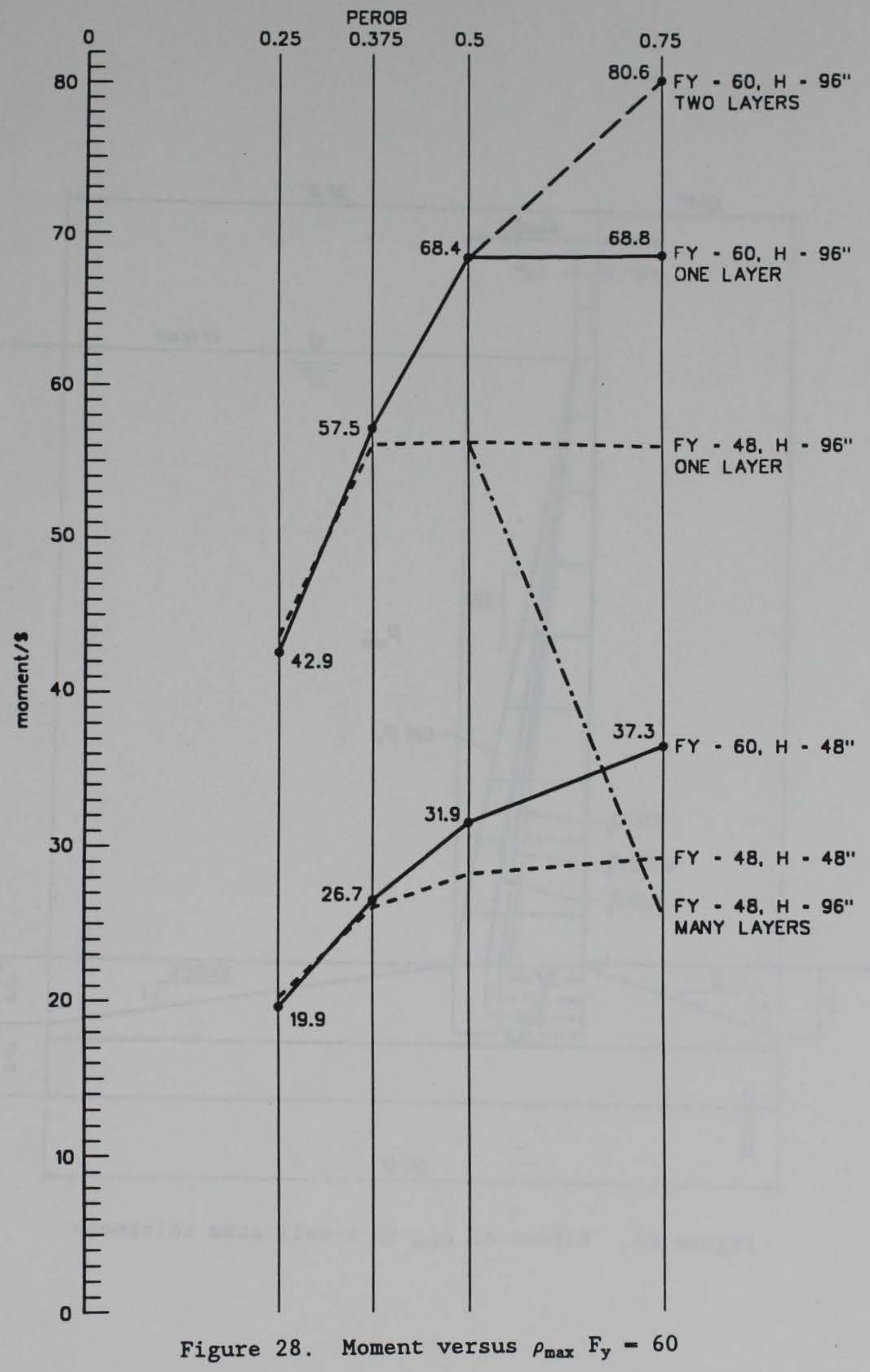




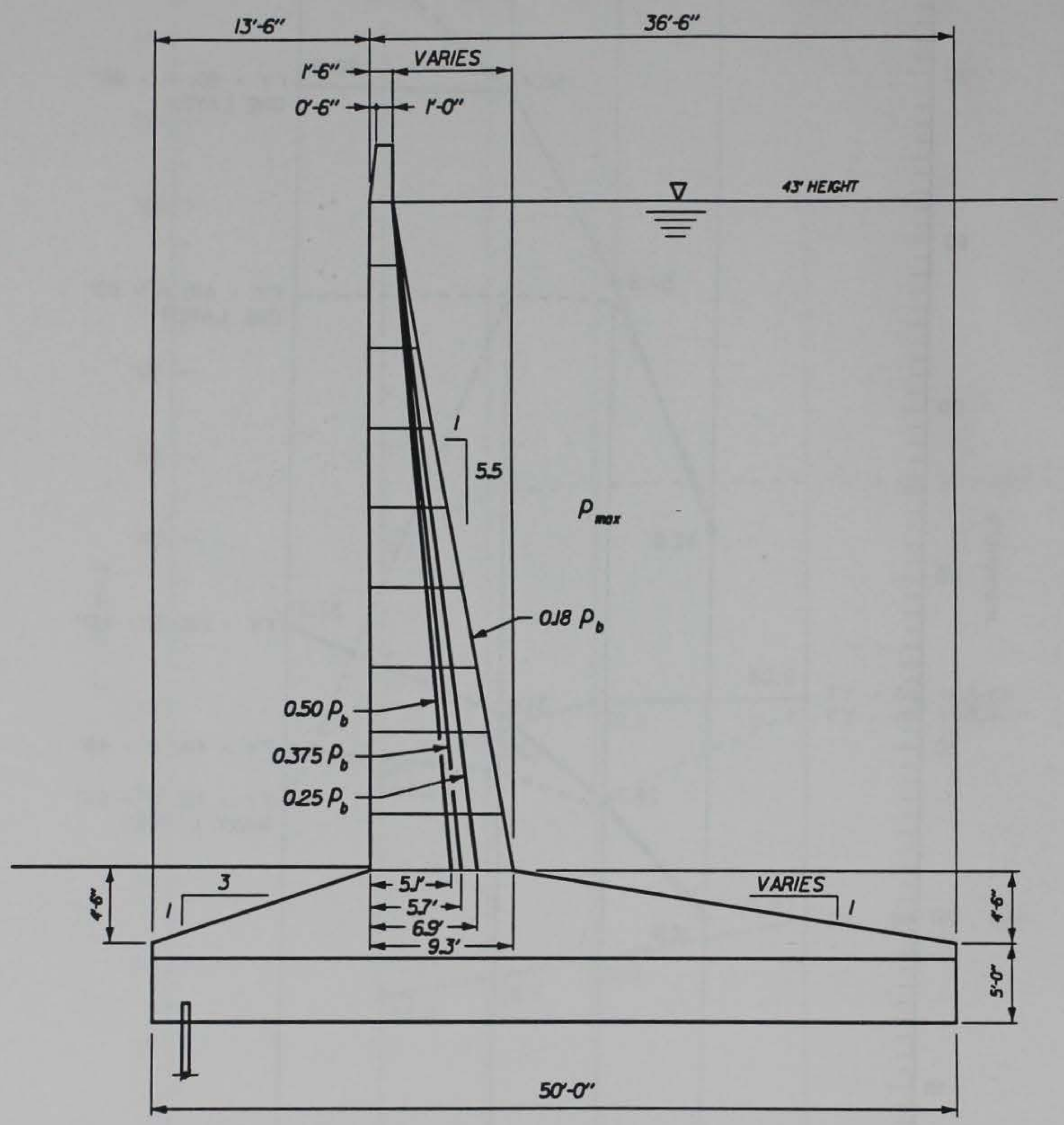

Figure 29. Effect of $\rho_{\max }$ on $t$-wall stem thickness 